\title{
REESCRIBIENDO LA HISTORIA. \\ ALGUNAS REFLEXIONES SOBRE EL CONOCIMIENTO Y DOMINIO DEL TERRITORIO NORORIENTAL DE MAGALLANES (1870-1900)
}

MATEO MARTINIC B. ${ }^{\text {a }}$

\section{RESUMEN}

En 1843 la República de Chile tomó posesión del estrecho de Magallanes y sus territorios reivindicando así el derecho que le venía desde la época del dominio hispano (siglo XVI). La ocupación se hizo efectiva inicialmente con una guardia de soberanía en la punta de Santa Ana (costa oriental de la península de Brunswick), trasladada posteriormente a la punta Arenosa (1848). Allí surgió el establecimiento de Punta Arenas que debía servir de base para la colonización del vasto territorio circundante. Tal propósito, sin embargo, se vio dificultado al hacerse del mismo un presidio militar, situación que sólo pudo comenzar a revertirse a contar de 1868-70. Para entonces las facilidades otorgadas para la inmigración libre y la atinada conducción del gobernador Oscar Viel (1867-74) hicieron posible el aumento de la población, la llegada de colonos y las primeras actividades económicas. Estas en particular impulsaron la expansión sobre el vasto hinterland situado al norte y noroeste de la colonia hasta su límite natural en el río Santa Cruz. Factores de ese fenómeno fueron los baqueanos que abrieron el camino del conocimiento territorial a los traficantes y a los exploradores científicos. Luego, en una segunda fase iniciada en 1878 y extendida hasta el término del siglo XIX, se realizó paulatinamente la ocupación colonizadora estable y permanente a través de la introducción y desarrollo de la crianza ovejera extensiva que en pocos años devino la estructura vertebradora de la economía y el desarrollo general del territorio patagónico austral. Entre tanto se definieron las jurisdicciones nacionales chilena y argentina sobre el ámbito geográfico meridional y se mantuvo la antigua y pacífica relación con los aónikenk, dueños ancestrales del territorio continental. Se formulan diversas reflexiones sobre cada uno de esos tópicos, como acerca del conocimiento geográfico como factor de posesión territorial y sobre las alternativas que tuvo la definición jurisdiccional de los países interesados, situación definida con el Tratado de Límites de 1881.

PALABRAS CLAVE: conocimiento geográfico, jurisdicción territorial, explotación económica, aventureros y exploradores, Patagonia sudoriental, indígenas.

a Profesor Titular y Emérito, Centro de Estudios del Hombre Austral. Instituto de la Patagonia, Universidad de Magallanes. mateo.martinic@umag.cl 


\section{REWRITING THE HISTORY. THOUGHTS ABOUT THE KNOWLEDGE AND DOMAIN OF THE NORTHEASTERN TERRITORY OF MAGALLANES (1870-1900)}

\section{ABSTRACT}

In 1843 the Republic of Chile took possession of the Strait of Magellan and its territories, restoring a right that started with the Spanish conquer (XVI century). This occupation was initially carried out by guards of sovereignty at Santa Ana point (eastern coast of Brunswick peninsula), afterwards moved (1848) to Sandy point. The establishment of Punta Arenas city then was used as a base for the colonization of the vast surrounding territory. This purpose, though, was made difficult by the constitution of a military prison, and this situation could only be reverted from 186870 onward. Then the opportunities given to free migration and the good commanding of Governor Oscar Viel (1867-74) made possible a population increase, the arrival of settlers and preliminary economic activities. Particularly, this encouraged the expansion over the extended hinterland located north and northwest of the colony up to the natural limit of the River Santa Cruz. Baqueanos or fieldsmen were factors of this phenomenon and opened pathways with territory information for traders and scientific explorers. Later in a second initial phase in 1878 and extended to the end of the XIX century a stable and permanent colonizing occupation was done through the introduction and development of extensive sheep breeding, that in a few years became the main structure of economy and general development of the Southernmost Patagonia territory. Meanwhile the Chilean and Argentinean jurisdictions were defined for the Southern geographic realm and the old and quiet relation with the Aonikenk people was sustained. Certain comments are suggested in relation to each topic, and for the geographic knowledge as an element of territorial possession and regarding the alternatives that the national jurisdiction definitions had for the involved countries, situation handled with the Treaty of Limits of 1881.

KEY WORDS: geographic knowledge, territory, economic exploitation, adventurers, explorers, Patagonia, indigenes.

\section{INTRODUCCIÓN}

Hace cosa de seis décadas y algo más cuando cursábamos los cursos universitarios de Derecho y pensábamos en algún tema para nuestra posterior tesis de grado, acabamos eligiendo una materia que, además, ofrecía las posibilidades de ampliar y profundizar la información hasta entonces disponible sobre la misma. Se trataba, en síntesis, de llevar adelante una investigación que pusiera en evidencia las decisiones y sus formas que habían permitido establecer la jurisdicción de Chile sobre las tierras australes del continente, precisando en lo posible los hechos y sus circunstancias. En el desarrollo de ese propósito académico la búsqueda de información en bibliotecas y archivos documentales fue no sólo una tarea obligada, por necesaria, sino también una faena intelectual interesantísima como revelación de un pasado que todavía permanecía parcialmente desconocido.
El objetivo preciso de nuestro trabajo era el de encontrar y describir las acciones y hechos, con sus consiguientes motivaciones, que en el curso del tiempo que siguió a la toma de posesión nacional del estrecho de Magallanes y sus territorios (1843), permitieron el conocimiento y paulatino dominio del vasto espacio geográfico a través de la ocupación pacífica y el inicio y desarrollo de actividades económicas primarias, apreciando el proceso como un paso necesario para reafirmar y consolidar los títulos históricos de jurisdicción sobre la región meridional americana que la República heredara de la antigua Capitanía General de Chile. Ello, es claro, en el contexto comprensivo de la controversia suscitada con la Confederación Argentina a contar de 1847, que también reclamó su propia jurisdicción sobre tal territorio, cuestión cuya solución se prolongó por espacio de tres y media décadas y que al fin encontró término satisfactorio para las partes, 
en lo general, en una suerte de transacción en cuya virtud Chile conservó el dominio del estrecho de Magallanes incluyendo una parte menor de la Patagonia oriental y la Tierra del Fuego, exceptuando la porción este de la isla grande homónima que se reconoció como de pertenencia argentina del mismo modo que la mayor parte de la Patagonia oriental. El acuerdo correspondiente se materializó en el tratado de límites suscrito en Buenos Aires el 23 de julio de 1881.

En este entendimiento si fueron relevantes los títulos que cada república pudo exhibir en defensa de sus reclamos, no lo fueron menos -e inclusive más decisivos- los hechos de posesión realizados en el territorio en disputa que permitieron establecer $\mathrm{y} / \mathrm{o}$ afirmar las correspondientes pretensiones. De allí que, a nuestro juicio, cabía buscar, examinar y ponderar todo cuanto se refería a esta última situación para conseguir una mejor apreciación histórica acerca de lo acontecido y, en particular, sobre cuanto se refería a la manera en que Chile -sus autoridades y agentes- habían actuado en la mejor defensa del interés nacional en vista de los resultados tangibles del proceso. El fruto de tal esfuerzo académico devino nuestra primera obra historiográfica Presencia de Chile en la Patagonia Austral 1843-1879 (Editorial Andrés Bello 1963, edición revisada y ampliada en 1971).

Fue tal el interés que nos generó este trabajo, devenido cosa apasionante, que el mismo motivó nuestra labor historiográfica posterior de modo que en el transcurso del extenso lapso corrido desde los años de 1960 hasta el presente proseguimos indagando $e$ informándonos sobre la materia y entregando nuevas consideraciones en artículos, monografías y libros. Ello fue posible, asimismo, porque se fueron desvelando $y$ conociendo sucesivos nuevos antecedentes $y$ noticias que han permitido iluminar lo acontecido en el espacio geográfico patagónico sudoriental en lo tocante al proceso de conocimiento preliminar y de ulterior paulatina ocupación con propósito económico cuyo origen y fuerza impulsiva estuvieron en la colonia chilena de Punta Arenas, hasta conseguir el establecimiento de la presencia humana permanente sobre el mismo con el desarrollo de actividades productivas.

Cabe recordar que para mediados del siglo
XX la información conocida (impresa) sobre esta materia se reducía a unos pocos títulos que, importa señalarlo, únicamente contenían referencias generales para el asunto de nuestro interés, todos por lo común de antigua data y por ello solamente disponibles en bibliotecas o librerías de viejo. Fue recién a partir de los años de 1960 que se reeditaron en Argentina las principales de esas obras, como las debidas a George Ch. Musters, Francisco P. Moreno y Carlos M. Moyano, entre otras, a través de las cuales el lector interesado en temas patagónicos pudo informarse sobre tantos aspectos propios de esa temática general.

A estas obras clásicas se fueron añadiendo con el correr de los años nuevas noticias históricas en forma de artículos y libros, frutos por lo común de investigaciones o hallazgos, con los que la información se ha completado y precisado ofreciéndose ahora la posibilidad de brindar una visión ciertamente satisfactoria en su comprensión acerca del ambiente natural y la vida en una región de frontera colonizadora como es aquella que nos interesa. Este es justamente el aspecto sobre el que pasamos a abundar a continuación.

Lo que nos interesa considerar en esta revisión de lo escrito otrora, más que enfatizar en las acciones oficiales de contenido político, aspecto ya tratado en nuestra obra precedentemente mencionada, es poner de relieve la participación de la gente común en el fenómeno de la expansión del ecúmene magallánico, en tanto que agente del conocimiento geográfico, la explotación primaria de recursos naturales y promotores o actores del comercio con los indígenas aónikenk y, de ese modo, en factor determinante o fundante de una hegemonía territorial devenida al fin jurisdicción nacional definitiva.

\section{LA PROGRESIVA COMPRENSION DEL MEDIO NATURAL Y LA PENETRACION EN EL ESPACIO GEOGRAFICO ESTEPARIO}

\section{a) Período $1843-1867$}

En la época en que el gobierno del presidente Manuel Bulnes adoptó la decisión de ocupar el estrecho de Magallanes y sus territorios a nombre de la República de Chile, el conocimiento que se poseía sobre los mismos era 
absolutamente nulo ${ }^{1}$; es más, si alguna noción había era la que pervivía por la tradición colonial referida a la de ser aquella región una zona salvaje $e$ inhabitable por la rudeza de su naturaleza y su clima, imagen ciertamente construida a base del recuerdo de la tragedia con que había concluido el intento colonizador de Pedro Sarmiento de Gamboa entre 1584 y1590. No obstante ello, curiosamente el antiguo sitio del funesto acontecimiento hispano rebautizado como "puerto del Hambre" (o Famine), fue entonces el elegido para instalar el asentamiento chileno por tratarse del lugar más conocido y ser, eso sí, un buen puerto para fondear naves.

Por ello la primera experiencia válida sobre las condiciones naturales del territorio y su habitabilidad se tuvo precisamente con el viaje de la goleta Ancud, embarcación de la Armada de Chile con la que se realizó la histórica expedición posesoria, cuando se advirtió que superado el meridiano del cabo Froward en el trayecto occidente-oriente $\left(71^{\circ} 20^{\prime} \mathrm{O}\right)$, el paisaje magallánico comenzaba a mutar sensiblemente según se avanzaba hacia el norte y noreste, y más todavía una vez que tras el viaje de reconocimiento efectuado a continuación del acto posesorio en la punta de Santa Ana se sobrepasó la primera angostura del Estrecho, momento en que se tuvo claro que el sector oriental del paso interoceánico era el que parecía ofrecer algunas ventajas para el poblamiento civilizado.

Esta noción preliminar se pudo afirmar una vez transcurridos los primeros años del asentamiento nacional en el territorio. Tal se infiere de dos informes científicos exhumados hace cosa de tres lustros: Bosquejo de la historia natural de Magallanes y de las costumbres de sus habitantes, de autoría inicialmente desconocida pero que ahora puede atribuirse al capitán Buenaventura Martínez y al cirujano Napoleón Gobert, ambos de la Armada de Chile, y que hemos datado hacia 1847, y, Observaciones concernientes a la Costa Patagónica del estrecho de Magallanes, elaborado por el cirujano José María Betelú en 1848 ó 1849 y que diéramos a conocer con nuestros comentarios años atrás ${ }^{2}$. Pero, sin duda alguna, es la monografía escrita por el gobernador Jorge C. Schythe, bajo el título de El Territorio de Magallanes i su colonización, publicada en los Anales de la Universidad de Chile en julio de 1855, el documento que ofrece la descripción más fiable, al cabo de una experiencia de vida de doce años en la costa del Estrecho y con un acervo acrecido de informaciones y registros escrito por un hombre que poseía indudable preparación como naturalista. Este documento, como los dos anteriores, debe ser especialmente considerado en el contexto comprensivo que las autoridades coloniales se habían formado acerca de la habitabilidad del territorio fretano en vista de la sustentabilidad y permanencia del establecimiento de Punta Arenas, aceptado, además, sin cuestionamiento de su pertenencia nacional en una época en que la pretensión de la Confederación Argentina sobre el territorio magallánico se mantenía larvada ${ }^{3}$.

Pues bien, en este trabajo monográfico concluido en septiembre de 1854 y cuya publicación en la revista universitaria mencionada correspondiente al año siguiente ocupó treinta páginas (caja de 18 x 10,5 cm y 51 líneas de texto por página), la parte referida a la sección centro-oriental y norte del territorio (las pampas patagónicas), ¡sólo le dedica cuatro líneas!: Aquí estamos en el confín de la península de las
1 Véase para el caso el Album de la República de Chile, por Claudio Gay, publicado en 1856 y tenido por la primera publicación del género geográfico y natural del país en su etapa de formación republicana (Hernán Maino editor, Consejo Nacional de la Cultura y las Artes, Santiago 2009). Ver especialmente en pág. 32 la referencia a la carta del autor a Manuel Montt de 1843 (nota 25), también la de págs. 37 y 38 (Nota 28) y el mapa "Estrecho de Magallanes" al final del Apéndice Cartográfico.

2 Martinic, M. (2001). Documentos inéditos para la historia de Magallanes. Anales del Instituto de la
Patagonia, Serie Ciencias Sociales, 29, 211-238.

3 De hecho, aunque el reclamo por la posesión chilena de 1843 se había formulado en 1847, nada más sucedió y recién con el Tratado de Paz, Amistad, Comercio y Navegación suscrito con Chile en 1856 se hizo una referencia indirecta (art. 39) al señalarse que ambos países se reconocian recíprocamente como límites entre sí los que poseían en su condición de antiguas dependencias coloniales al separarse de España en 1810 y que las cuestiones que se hubieran suscitado o que pudieran suscitarse sobre la materia se resolverían pacíficamente o, en caso de desacuerdo, por el arbitraje de una nación amiga. 
colonias [Brunswick, de la que se ha ocupado extensamente como sección principal] El paisaje ha mudado de carácter insensiblemente, i con sentimiento echamos de menos las fecundas vegas $i$ praderas que hemos dejado atrás.

Dirijiendo la vista al oeste i norte, no se descubre objeto alguno que interrumpa la triste monotonía de la dilatada pampa. Eso, de momento pareció bastar respecto de ese extenso e ignoto ámbito dominio de los legendarios patagones ${ }^{4}$.

El litoral patagónico al norte de Punta Arenas, más allá del cabo Negro (lat. $53^{\circ}$ sur), no llamó inicialmente la atención de sus habitantes. Las costas se sabían parejas, llanas y monótonas, en verdad poco atractivas por sus características esteparias. Sólo Bernardo Philippi, observador agudo como era, había apreciado en 1843 sus pasturas como un eventual recurso económico. En cuanto a las tierras del interior, respecto de ellas había el misterio absoluto y tan sólo los indígenas patagones (aónikenk) con los que en un principio no resultaba fácil entenderse podían saber algo, pero, de momento, sobre esa inmensidad que eran "las pampas" como prontamente comenzó a mencionarse esa parte del territorio no había interés. Qué decir de la Tierra del Fuego, del otro lado del Estrecho, tan inmensa como desconocida, que tampoco interesaba a ninguno, con lo escasos que eran los habitantes de la colonia de Punta Arenas y con la miserable índole de aquellos pocos que podían considerarse libres durante el lapso que siguió a su fundación y a su repoblación tras el motín de Cambiazo (1851) y hasta mediados de los años de 1860; bastaba y sobraba pues con el estrecho ámbito comarcal del establecimiento. Más allá, su entorno era un territorio ignoto, un mundo enteramente ajeno.

Así entonces, el espacio geográfico necesario para ver cumplido el objetivo inicial de un asentamiento soberano de Chile en el Estrecho era más bien pequeño, es decir aquel que de acuerdo con sus condiciones naturales (tierra laborable, agua corriente, disponibilidad de bosques maderables, recursos cinegéticos variados $\mathrm{y}$, al parecer, disponibilidad de mineral de carbón por

Op. cit. Pág. 447. Lo destacado es nuestro.

Para mayor información sobre la materia véase del autor Punta Arenas en su primer medio siglo, 1848-1898 añadidura, cuya existencia generaría los primeros sueños de desarrollo), era el que debía bastar para garantizar un desenvolvimiento asegurado aunque modesto. Y para ese restringido primer ecúmene bastaba según los conocimientos obtenidos y la todavía corta experiencia de vida utilizar el reducido espacio conformado por el litoral oriental de la península de Brunswick, acotado entre la bahía de Agua Fresca por el sur y la de Laredo o el inmediato cabo Negro por el norte, entre las costas del Estrecho y la boscosa serranía que corre en una suerte de línea paralela tierra adentro. Era este espacio, importa recordarlo, el distrito fretano que tan gratamente había impresionado a los navegantes científicos del siglo XVIII, quienes en sus planos y relaciones consignaban menciones del tipo de...aquí comienza la buena tierra... para describir la mutación paisajística apreciable según se navegaba Estrecho adentro procediendo desde el Atlántico. Y así efectivamente bastó entre 1853 (tiempo de la reocupación y repoblamiento de Punta Arenas tras su destrucción por el motín encabezado por el desalmado teniente Miguel José Cambiazo) y 1868 (época del comienzo de la vigencia de las medidas de fomento dictadas por el gobierno del Presidente José Joaquín Pérez), lapso durante el que la equivocada política gubernativa y la irresolución respecto del porvenir de la colonia, hicieron que esta no pasara de ser otra cosa que un miserable establecimiento penal-militar, poblado por un puñado de funcionarios, un contingente mayor de presidiarios y por los soldados destinados a su custodia, amén de sus correspondientes familias -nunca más de 200 almas en promedio durante tres lustros-, en el que unos y otros dependían del Estado para su mantenimiento y del que estaba ausente toda posibilidad de actividad productiva útil ${ }^{5}$.

Lo poco, poquísimo que sobre el territorio nororiental pudo saberse -ser un espacio de enorme e indeterminada amplitud hacia el interior, de cansadora monotonía paisajística por su fisionomía orográfica plano-ondulada y vegetacionalmente de carácter estepario (únicamente pastos y matorrales aislados); un país sempiternamente ventoso (así se creía) y poblado por avestruces y guanacos, las

(Edición del autor, Punta Arenas 1988), especialmente el capítulo "Los años del letargo 1852-1867", en págs. $73 / 128$. 
especies más visibles. Tal noción pudo extenderse y ampliarse, como dependencia de Punta Arenas, corriendo los años hasta el estuario del río Gallegos en el Atlántico, paraje hasta el que alcanzó en 1853 el gobernador Schythe en lo que, debe aceptarse, debió ser toda una expedición esforzada. Lo que contribuyó a generar a la larga una indefinible noción de pertenencia jurisdiccional chilena fue el hecho de las ocasionales fugas de presidiarios que no tenían más opción para la libertad que la de internarse en las pampas, cruzar el Gallegos y alcanzar hasta el más distante estuario del río Santa Cruz, en cuya persecución solían enviarse partidas de soldados. Pero, así y todo, tal "jurisdicción" debe ser considerado como cosa meramente teórica. Esa fue, por años, la única razón que pudo darse para alejarse de la colonia chilena (Fig. 1).

\section{b) Período $1868-1870$}

Todo hubo de cambiar a contar de los años 1865-66, época en la que concurrieron dos circunstancias para que tal mutación fuera posible. La primera, con carácter de determinante por el revuelo que en su hora provocó, fue el resurgimiento notorio de las aspiraciones de jurisdicción argentina sobre la región del estrecho de Magallanes que hasta entonces se habían mantenido larvadas.

En efecto, hacia principios de 1865 la autoridad colonial de Punta Arenas se enteró de la existencia de una misteriosa "Comisión Exploradora de la Patagonia" cuyo propósito y actividad aparentes estaban referidos a la instalación y afirmación de la presencia jurisdiccional argentina en el litoral nororiental del estrecho de Magallanes. Ello, según se supo después, había sido iniciativa del capitán lobero y traficante de la misma nacionalidad Luis Piedra Buena, que desde 1859 mantenía un modesto establecimiento mercantil para el comercio de trueque con los indígenas patagones (aónikenk) en el islote Pavón, estuario arriba del río Santa Cruz, planteado como expresión de soberanía de su país en el ámbito austral patagónico. Concertado para el efecto con el voluble jefe aónikenk Casimiro Bigua, habían visitado el año anterior al Presidente Bartolomé Mitre, oportunidad en la que aquél

6 Para una mayor y más completa información sobre la materia véase nuestra obra precedente citada (págs. 115 le había informado al mandatario acerca de su propósito consistente en la fundación de una colonia argentina en la costa de la bahía de San Gregorio, con la participación activa de la indiada aónikenk según lo prometía Casimiro, para lo cual se había pedido la aprobación y apoyo variado del gobierno de Buenos Aires. Sin embargo de haberse obtenido lo primero y la promesa de lo segundo, el proyecto de momento no pudo materializarse, pero el eco de esas gestiones difundido por los indígenas pudo llegar meses después hasta Punta Arenas y despertar la preocupación de la autoridad a cargo de la misma. Aunque el asunto no pasó entonces de un alarmante rumor, con visos de bravuconada, lo ocurrido bastó para despertar el interés de la autoridad colonial por el territorio situado allende el linde comarcal del establecimiento chileno, en primer término para informarse mejor sobre sus características y luego para impulsar alguna acción de afirmación jurisdiccional con el fin de frenar la mencionada pretensión ${ }^{6}$.

La otra circunstancia que contribuiría a un cambio en la situación precedentemente descrita estuvo ligada, como debía ser, al aumento de la población del establecimiento de Punta Arenas. Mientras allí no hubo más que los confinados (presos), los soldados destinados a su custodia y los contados funcionarios del gobierno y la administración, amén de algunos artesanos contratados por el Estado, y sus correspondientes familiares cuando los había, no se dio ninguna posibilidad de actividad por cuenta propia, circunstancia que sólo vino a ser posible una vez que, a partir de 1866, arribaron los primeros individuos libres, esto es, sin vinculación alguna con el Estado aunque todavía no podía llamárseles propiamente "colonos" -porque tal calidad no existía administrativamente $y$, por consecuencia, con capacidad para poder discurrir acerca de cómo emplear su tiempo con algún provecho en ese aislado y remoto destino de frontera-, que pudieron pensar en aventurarse por lo desconocido más allá de los límites comarcales, en plan de exploración y/o de caza, esta quizá la primera actividad útil que pudo venir a la mente, supuesta la abundancia de vida silvestre en la tierra ignota. Pudo también, de modo más específico, interesar la captura de

y sgts.) y Punta Arenas en su primer medio siglo 18481898. 
animales vacunos baguales originarios del hato que había quedado abandonado y libre a consecuencias del motín de Cambiazo y que se habían multiplicado viviendo en los bosques de la serranía que espalda a Punta Arenas y en las zonas de parque y llanuras de la vertiente opuesta hacia el mar de Otway. Las primeras expediciones con ese objeto habían sido dispuestas por la gobernación colonial en 1858 y 1859, a cargo de partidas de soldados y vaqueros, aunque con escaso éxito inicial debido al terreno en que debieron operar (boscoso, fragoso y quebrado) y a la movilidad del ganado bagual, aparte del mal estado de las cabalgaduras, pero sobre todo a la inexperiencia en ese tipo de faenas.

Pero todo comenzó a cambiar particularmente a contar del arribo a Punta Arenas del nuevo gobernador, capitán de corbeta Oscar Viel, de la Armada de Chile, en febrero de 1868 acompañado de un contingente ciertamente importante de colonos, conformado por sesenta jefes de familia (234 personas, incluyendo esposas e hijos) contratados en Valparaíso y Ancud bajo las favorables condiciones establecidas por el decreto presidencial de fomento a la colonización y la inmigración dictado en noviembre del año precedente. Era toda gente libre que había escogido la opción pobladora ofrecida y que en consecuencia debía ingeniárselas para ver y buscar la forma de ganarse la vida con seguridad y provecho. Eso, por cierto, no demoró en ocurrir pues ocupado el primer tiempo siguiente a la llegada de tanta gente en los trabajos y exigencias propios de la instalación como colonos (obligación de cierre de terrenos urbanos y erección de viviendas en ellos amén de otras faenas complementarias necesarias según lo convenido en los contratos de colonización correspondientes), al cabo de esa actividad ineludible por necesaria quedó gente ociosa (hombres adultos)

7 Esto precisamente fue lo ocurrido con George Ch. Musters, antiguo oficial de la Armada Real Británica, cuando planeaba la que después sería su memorable expedición transpatagónica de 1869-70 desde Punta Arenas hasta Carmen de Patagones (Cfr. Vida entre los Patagones. Ediciones Solar-Hachette, Buenos Aires 1964), págs. 54 y sgts.

8 El baqueano William H. Greenwood ha dejado una precisa y fidedigna mención sobre esta actividad referida a un paraje ubicado al poniente de Punta Arenas (Patagonia Bravía. Naturaleza, vidas y aventuras. Memorias originales del baqueano William H. Greenwood. Gladys G. Grace Paz y Duncan S. Campbell Editores. Santiago, 2016), págs. 67-68. que debía ocuparse en cosa útil y fue menester así discurrir en qué ocupar el tiempo con algún beneficio. La casualidad ayudó con el hallazgo de arenas auríferas en el río del Carbón que corría por el borde norte de Punta Arenas, pues ello bastó por un buen tiempo para mantener ocupados a muchos hombres en el lavado de arenas y en las faenas complementarias; otros pocos, quizás noticiados por los habitantes más antiguos advirtieron que el negocio de intercambio con los aónikenk, que de tanto en tanto arribaban a Punta Arenas desde las pampas con sus productos (pieles, plumas, artesanías), podía acrecentarse en beneficio propio si en vez de aguardarse la llegada de los indígenas se iba en su búsqueda territorio adentro $y$, de paso, con la seguridad de practicar buena caza de avestruces y guanacos que, según se sabía, abundaban en grandísima cantidad. Había entre la gente de antaño, además, más de un conocedor -antiguo soldado o preso liberado quizá- por haber integrado partidas de captura o grupos de fugitivos, que pudo aceptar servir de guía e incluso de copartícipe en esos proyectos cinegéticos y mercantiles ${ }^{7}$. Algún otro, igualmente avisado, pudo pensar, otra vez, en la captura de vacunos baguales tras las montañas del oeste, posibilidad ahora vista como negocio en verdad lucrativo habiendo que alimentar a tanta gente como a la arribada a partir de febrero de 1868 (sobre 500 personas hasta setiembre de ese año según cuenta del gobernador Viel $)^{8}$.

Complacido este sobre lo que acontecía y haciéndose eco de tal circunstancia pudo consignar en su primera memoria administrativa que...la necesidad los ha vuelto industriosos $i$ trabajadores [a los colonos], pues...se ocupan en trabajar sus huertos, otros en el oro y otros en el negocio con los indios...?.

Así pues para 1869-70 las condiciones

Menciones toponímicas sobre la actividad (Vaquería del Sur y Vaquería del Norte) se contienen en el Plano Topográfico de la Rejión Central Magallánica, por Alejandro Bertrand, escala 1:500.000, que acompaña su "Memoria sobre la Rejión Central de las Tierras Magallánicas presentada al Ministro de Colonización" (En Anuario Hidrográfico de la Marina de Chile, XI, 203-343. Santiago 1886).

9 Memoria presentada al Señor Ministro del Interior comprendiendo desde el 7 de febrero de 1868 hasta el 31 de mayo de 1871. (Correspondencia Ministerio del Interior. Gobernación de Magallanes 1869-1872). Archivo Nacional, Santiago. 
parecían dadas para iniciar la aventura de la penetración progresiva tierra adentro hacia el norte y el poniente de la colonia de Punta Arenas y, ciertamente, las mismas fueron bien aprovechadas desde un principio. Como prueba basta un dato aportado por la misma autoridad gubernativa: sólo en 1870 salieron de Punta Arenas 182 expediciones hacia las pampas con el objeto de negociar con los aónikenk y el año siguiente la cantidad superó las $300^{10}$ (Fig. 1).

\section{PENETRACION A LAS PAMPAS Y PRECORDILLERA ORIENTAL. CONOCIMIENTO DE LA GEOGRAFIA Y LOS RECURSOS NATURALES}

\section{Período 1871-1881}

a) Aónikenk, soberanos ancestrales del territorio

Aunque el objeto de esta parte del trabajo es la consideración de la forma, momentos y etapas de la penetración paulatina de los foráneos, en tanto que nuevos habitantes, en el territorio sudpatagónico, este aspecto no puede ser debidamente abordado sin una mención a la presencia indígena preexistente al arribo de los civilizados, en tanto que de cualquier modo el conocimiento inicial por parte de éstos provino de aquéllos.

Los aónikenk -patagones para los europeos desde Magallanes y Pigafetta, y tehuelches para sus cuasi vecinos septentrionales los mapuches-, remontaban su presencia por centenares de generaciones de las bandas de cazadoresrecolectores que arribaron $y$ se establecieron paulatinamente en el ámbito sudoriental continental a contar, de modo comprobado por la arqueología, desde el octavo milenio antes de nuestra era ${ }^{11}$.

De ese modo, a lo largo de milenios, generación tras generación habían conseguido adaptarse a las condiciones ambientales rigorosas con un dominio pleno de las características de la naturaleza en su compleja variedad, así como de la disponibilidad y utilidad de sus recursos, llegando a elaborar inclusive una cosmogonía que daba cuenta y explicaba el origen de las cosas y de la vida (Martinic, 1995). En suma, nada de lo que los humanos necesitaran para una existencia satisfactoria -en sus austeros estándares primitivos- les fue ajeno y lo lograron, vale reiterarlo, con un conocimiento, como el de otros pueblos originarios australes, en un grado tal que sorprende al estudioso de ogaño en la medida que penetra en su arcano existencial.

La buena índole manifestada por la etnia aónikenk para con los extraños, con los europeos especialmente, por otra parte y según lo hemos considerado con antelación (Martinic, 2013) y la interrelación así establecida a lo largo de tres siglos (desde el XVI al XIX), hizo posible como consecuencia no buscada intencionalmente por los foráneos la trasmisión de datos y noticias que no obstante que elementales y ocasionales fueron permitiendo, por efectos de la superposición o mera acumulación de información, obtener una comprensión preliminar acerca de las características de su vasto dominio territorial. Este proceso de ocasional pudo hacerse repetido a contar del siglo XIX según los antecedentes históricos disponibles, paulatinamente más amplios y profundos, sobre los contactos interétnicos.

En efecto, esas noticias estuvieron primeramente referidas a los indígenas en lo tocante a su existencia y cultura y fueron especialmente válidas y útiles tras los encuentros y relaciones establecidas por los foráneos con los aónikenk en diferentes lugares de la costa nororiental del estrecho de Magallanes, nociones y experiencias que fueron recogidas y conservadas en relaciones de informantes tales como Philip P. King y Robert Fitzroy, William Low (a través de aquéllos), John Macdouall, Charles Darwin, Jules C. Dumont D'Urville, entre varios de los navegantes que pasaron por el Estrecho en la primera mitad del siglo XIX, cuya difusión se generalizó a contar de los años de 1840. También en el caso de los primeros ocupantes chilenos ello ocurrió con lo escrito en los informes oficiales y en comunicaciones privadas entre 1844 y 1854 (Bernardo E. Philippi y los ya
10 Punta Arenas en su primer...(citada) pág. 149.

11 Como muestra elocuente del saber acumulado al cabo de investigaciones sistemáticas sobre la vida humana pretérita en el territorio austral americano, sugerimos recorrer tan sólo los índices o contenidos en los volúmenes de Anales del Instituto de la Patagonia después Magallania publicados desde 1970 en adelante hasta el presente por diferentes autores en los que se da cuenta de los estudios y trabajos desarrollados sobre la materia a lo largo de casi medio siglo con un impresionante resultado en lo referido a un mayor y más profundo conocimiento. 


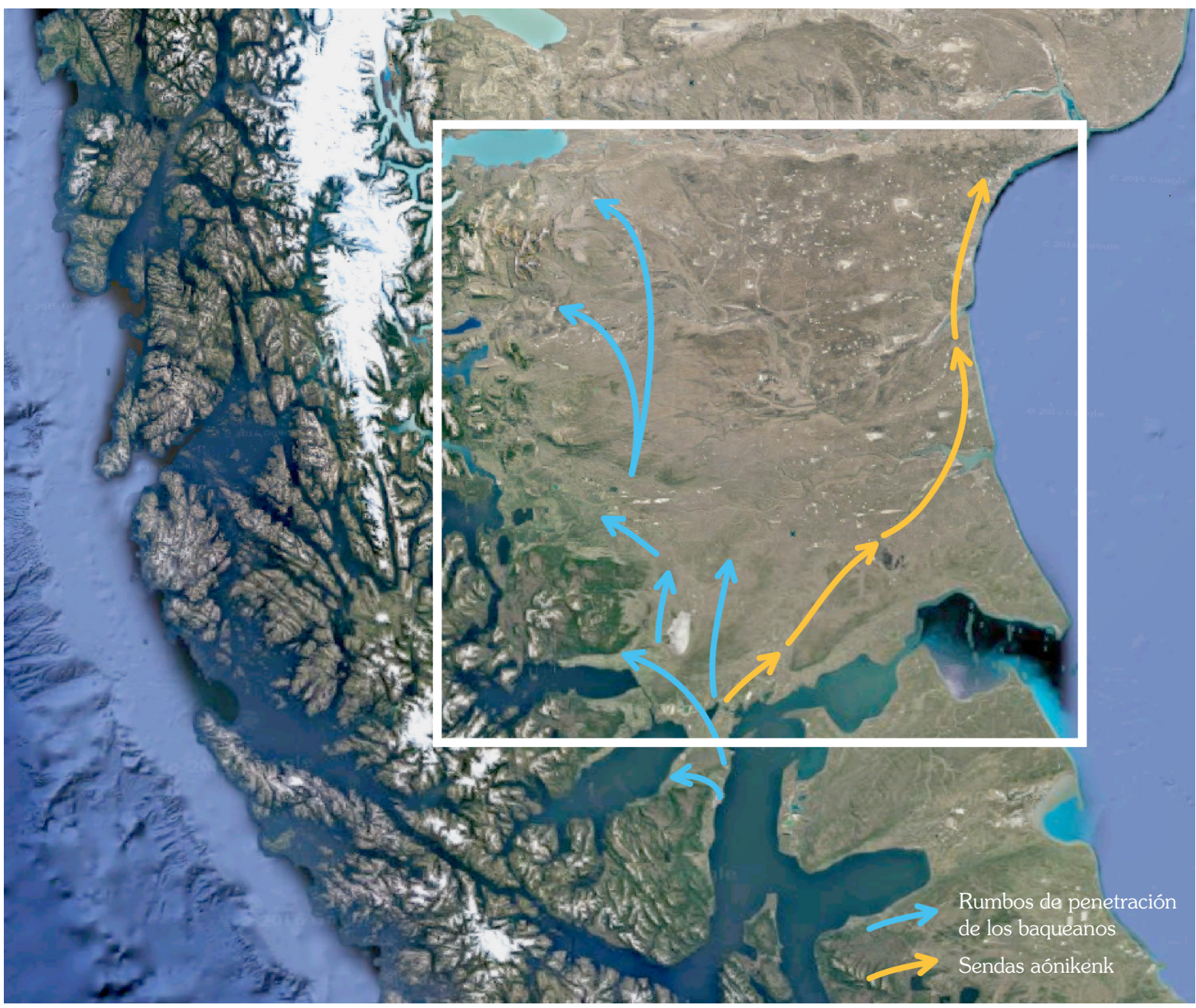

Fig. 1. Patagonia Austral entre $50^{\circ}$ y $54^{\circ}$ Sur. En recuadro zona centro-oriental (Las Pampas). Imágen Google Maps (C) 2016.

mencionados Betelú, Martínez, Gobert y Schythe). Las noticias propiamente geográficas sobre el país de los cazadores continentales nómadas comenzaron a tenerse tras las incursiones misioneras de William Arms y Titus Coan (1833) y de Teófilo Schmid (1858-63), de permanencias forzadas como fuera la del norteamericano Benjamin Bourne en 1849 y la voluntaria de Doroteo Mendoza, integrante sui géneris de la Comisión Exploradora de la Patagonia precedentemente mencionada (1865), y fueron cuidadosamente recogidas por las autoridades de Punta Arenas e inclusive por algunos de sus habitantes según lo que pudo llegar a trascender. Así, con lo poco añadido al cabo de cada expedición de captura de fugitivos, si la ocasión se había dado para ello, y con lo que pudo saberse mediante el trato con los indígenas durante sus periódicas visitas a Punta Arenas durante los años 1850 y 1860 , pudo disponerse sólo de una información más bien general, aunque vaga y poco precisa, apenas válida para los sectores de territorio por los que pasaba la ruta de tráfico de los indígenas, esto es por las secciones centro-oriental y oriental cercana a las costas fretana y atlántica, entre los lindes de aquel establecimiento y el estuario del río Santa Cruz. Pero, con ser escasa y deficiente tal noción elemental, pudo servir en su hora de base suficiente para originar y animar las primeras penetraciones aventureras individuales por la inmensidad del erial desconocido que en su desarrollo y transcurso permitieron interactuar con los indígenas que allí habitaban y acrecentar 
sustancialmente el conocimiento sobre vastas secciones del interior sudpatagónico ${ }^{12}$.

Se justificaría así la temprana percepción de los foráneos ajenos al establecimiento chileno del Estrecho, como fue el caso, entre otros, del misionero protestante Teófilo Schmid en cuanto que Punta Arenas era el umbral del mundo de los Tsóneka (aónikenk) ${ }^{13}$. En verdad, quien entonces y después requiriera información sobre las comarcas ignotas del interior del extremo austral del continente americano debía necesariamente llegar hasta ella y hacer de la misma su obligado punto de partida para una empresa en ciernes como esa. Paradigma de esta circunstancia fue lo acontecido en 1869 con el ya mencionado George Musters, quien valoró la acogida y el apoyo obtenido alli para su proyecto de viaje transpatagónico y que luego de un recorrido de más de dos mil kilómetros por tierras virtualmente ignotas para la civilización culminaría al cabo de un año en el poblado argentino de Carmen de Patagones. La pronta difusión impresa sobre lo acontecido en la memorable travesía ${ }^{14}$, afirmaría, de paso, la importancia de la ubicación de Punta Arenas como base operativa para la realización de otros eventuales eventos de la especie en el porvenir.

\section{b) Baqueanos, cazadores y traficantes}

En las zonas del mundo de poblamiento civilizado históricamente más reciente, esto es, en los últimos cinco siglos, como son los casos de América y Australia, tal fenómeno en su evolución en territorios de gran magnitud geográfica ha supuesto un

12 Para más información sobre la materia recomendamos consultar nuestro libro Los aónikenk. Historia y cultura (Ediciones de la Universidad de Magallanes, Punta Arenas 1995) y también nuestro artículo "Los aónikenk ¿epítome del buen salvaje? (Magallania, 41(1), 5-28, Punta Arenas 2013).

13 Carta fechada en Punta Arenas el 4 de julio de 1861, en Teófilo Schmid Misionando por la Patagonia Austral 1858-1865 (Academia Nacional de la Historia, Buenos Aires 1964), pág. 37.

14 En este aspecto el antiguo marino se manifestó tan buen difusor como explorador pues apenas corridos unos dos meses de su llegada a Buenos Aires desde Carmen de Patagones, con fecha 7 de agosto publicó en el periódico The Standard un resumen de su travesía. En seguida, ya de retorno en su patria, dio lectura a una comunicación más extensa sobre la misma en una sesión pública de la Royal Geographical Society realizada el 13 de diciembre de 1870, proceso progresivo de penetración desde las costas primeramente abordadas por los descubridores y exploradores, con el consiguiente establecimiento de asientos fundacionales $\mathrm{y}$, posteriormente, con el desarrollo de sucesivas etapas de penetración exploratoria y finalmente de ocupación permanente y definitiva. Ha sido común, de acuerdo con la literatura conocida que en estas etapas las fases propiamente pioneras hayan sido obra de unos pocos aventureros, generalmente individuos anónimos o poco conocidos, que llevados por la curiosidad como motivación estimulante incursionaron tierra adentro penetrando en los arcanos geográficos contribuyendo a develar sus misterios. Estos "gastadores" de la civilización ${ }^{15}$ han cumplido así un papel relevante que merece ser reconocido y destacado en la labor historiográfica. En lo tocante a la Patagonia austral -específicamente el nororiente magallánico- cuanto atañe a su conocimiento ha sido materia de un especial interés personal. Tanto ha sido así que nos hemos dedicado a ella de forma reiterada (Martinic 1964, 1977a y b, 1978, 1979, 1983, 1984), al ocuparnos de estos individuos ciertamente singulares conocidos en su hora con la denominación de "campañistas" e históricamente como baqueanos ${ }^{16}$.

Tras esta necesaria explicación introductoria será posible entender mejor el importante papel protagónico que ocupó a cuantos se desempeñaron como tales en el ignoto teatro geográfico que era la Patagonia sudoriental hacia 1870.

El origen de este curioso oficio, ya se ha visto, se dio en las circunstancias que concurrieron en la colonia de Punta Arenas a partir de 1868 y que

un resumen de la cual fue publicado en los Proceedings de la entidad (1871) y en forma completa en su Journal del año 1872 . Esta última publicación fue traducida y publicada en Santiago de Chile por Francisco Fonck en el curso del mismo año. Entretanto así ocurría Musters se dedicó a la preparación de un relato extenso y completo del viaje que, bajo el título de At home with Patagonians, se publicó en Londres durante 1871. La gran acogida brindada al libro exigió una segunda edición en 1873, año en que, además, se publicó una traducción en alemán (Jena 1873). El mundo culto, tuvo así reiteradas oportunidades para informarse sobre el viaje y para actualizar las informaciones geográficas hasta entonces disponibles sobre la Patagonia.

15 Así se denominaba en los antiguos ejércitos a los hombres que iban por delante de las vanguardias explorando el terreno como rastreadores.

16 Práctico de los caminos, trochas y atajos (Diccionario de la Lengua Española, XIX edición, Madrid, 1970). 
importa recordar: aumento del número de habitantes libres y necesidad de dar una ocupación honesta y de provecho a tanto varón adulto ocioso o disponible $\mathrm{y}$, no habiéndola entonces en grado suficiente dentro de sus acotados lindes comarcales, fue necesario aguzar el ingenio en su procura. Eran estos la típica situación y el ámbito territorial a la vista propios de una región de frontera de la colonización.

Personificando en quien fuera su arquetipo, Santiago Zamora, y siguiendo a Juan T. Rogers que entregó las primeras noticias sobre este personaje -que precisamente le había sido recomendado por su baquía para ser como guía en su expedición de 1877 al lago Santa Cruz-, aquél había llegado a Punta Arenas en 1868 en calidad de colono, pero luego de su llegada, no aviniéndose a su nueva vida, volvió a sus anteriores hábitos, haciéndose vaquero ${ }^{17}$, sabemos así que el ejercicio de esta actividad, que según parece había sido su antiguo oficio antes de emigrar a Magallanes, ahora en la forma de cazador de vacunos baguales (cerriles), fue la actividad que decidió su destino. Este antecedente ha sido confirmado por William H. Greenwood en sus memorias quien en ellas ha dejado la mejor semblanza de ese baqueano, su amigo y compañero de correrías por cerca de una década. En efecto, afirma haberlo conocido no bien el inglés arribó a Punta Arenas en $1870^{18}$ encontrándose con él y otros compañeros en su campamento de caza de vacunos baguales situado en la proximidad de la costa del mar de Otway, del lado occidental de la península de Brunswick, hasta donde llegaron Greenwood y su amigo John Leesmith tras remontar y cruzar la

17 Expedición a la parte austral de la Patagonia por el teniente $2^{\circ}$ de la Armada de Chile señor Juan Tomás Rogers (en Marinos de a caballo. Exploraciones terrestres de la Armada de Chile en la Patagonia austral y la Tierra del Fuego 1877-1897. Edición de Mateo Martinic, Universidad de Magallanes-Universidad de Playa Ancha, Valparaíso 2002), pág. 25.

18 En carta inédita escrita en época indeterminada y dirigida a uno de los hijos de su difunto amigo Henry L. Reynard, Greenwood data su arribo a Punta Arenas el 12 de diciembre de 1870 (información obtenida por gentileza de Duncan S. Campbell). En rigor histórico Greenwood fue el primero de su nacionalidad que se estableció en Punta Arenas como inmigrante, seguido tiempo después por James Dunsmuir y Henry L. Reynard, antes de 1872.

19 Greenwood sugiere en su obra citada, al mencionar el punto de la captura de vacunos, que los mandatarios coloniales habrían tenido algún interés personal en ella vista como un negocio, pero en verdad (hasta Oscar Viel a lo menos) lo serranía de las espaldas de la colonia en plan de caza y de búsqueda de oro.

Por entonces Zamora desarrollaba esa actividad, harto lucrativa al parecer, para proveer de carne a la colonia y también, cuando fue el caso, para su venta a la autoridad colonial que buscaba acrecentar la dotación de ganado mayor de propiedad fiscal, lo que le permitió acceder a comarcas y distritos cada vez más alejados de Punta Arenas hacia el noroeste y el norte de la misma ${ }^{19}$. Siempre aventurando con rumbo al septentrión y posiblemente relacionándose periódicamente con los aónikenk llegó al valle superior del río Gallegos y desde allí accedió hasta los atractivos distritos subandinos de Última Esperanza y del sudoeste del lago Santa Cruz (Argentino). Ello debió suceder, conjeturamos a falta de datos precisos, entre 1870 y 1874, pues la primera referencia concreta es la contenida en la Memoria de la Gobernación de Magallanes correspondiente al período 187374 (fechada el 1 de mayo de 1874), en la que el gobernador Oscar Viel señalaba textualmente al dar cuenta de la dotación de ganado de propiedad fiscal en la colonia (850 vacunos y 382 caballares contados en enero de ese año): Últimamente se ha descubierto un lugar en las Cordilleras distantes algunas decenas de leguas de esta Colonia un numero considerable de caballada, que al decir de los que han visto no bajan de tres $m^{2} l^{20}$. Añadía Viel que se habían enviado varias expediciones y que ya se habían traído no menos de 50 animales ${ }^{21}$.

que habían hecho ellos no había sido más que defender el interés fiscal por cuanto el ganado mayor era una especie de bien público que, por una parte, permitía asegurar la alimentación de la población de Punta Arenas (incluido por cierto el mantenimiento de los confinados y sus familias) y, por otra, disponer del suficiente número de cabezas bovinas para atender la obligación de suministro de animales de acuerdo con los contratos de colonización.

20 Correspondencia Colonización de Magallanes 1874 -75 (Archivo Ministerio de Relaciones Exteriores, Santiago).

21 Este dato preciso permite cruzar esta información, corroborándola, con lo relatado por Greenwood en sus memorias (op. cit, pág. 62), al recordar su primera expedición en compañía de Zamora al remoto distrito subandino que después sería llamado Cañada de los Baguales, oportunidad en que consiguieron capturar varias decenas de caballos salvajes, de los que un medio centenar pudo ser arreado hasta Punta Arenas y vendido a la Gobernación. 
Zamora fue así, por su indiscutida primacía, el auténtico adelantado del conocimiento geográfico referido al interior del territorio sudpatagónico oriental. Con él como pionero, los baqueanos revelaron el misterio de las ignotas regiones del continente. Su reconocimiento fue previo y necesario para la exploración científica posterior. Casi toda la precordillera oriental desde el mar de Skyring hasta el lago que después se nombraría San Martín fue descubierta y recorrida por ellos hasta donde pudieron alcanzar sus cabalgaduras o a pie. Desde los valles y llanuras de los ríos Canelos y Grande, comarca que llamaron "Vaquería del Sur", en la vertiente occidental de la península de Brunswick, pasando por las tierras bañadas por el canal Fitz Roy y el mar de Skyring, la "Vaquería del Norte", orillando por el occidente hasta la cordillera Pinto y los cordones serranos "del Penitente", comprendiendo todos los campos del oeste y norte de la laguna Blanca hasta los valles medio y superior del río Gallegos y sus tributarios; y hacia el norte los valles, serranías y cuenca lacustre interior de Última Esperanza y del lago Santa Cruz, y aun allende el río homónimo hasta los lejanos lagos Viedma y San Martín; y en la zona esteparia, la costa y las mesetas centrales, todo fue reconocido y recorrido por esos recios solitarios.

Tan intenso recorrer llegó a conformar "senderos de los baqueanos", que para las Vaquerías del sur y del norte partían desde Chabunco por el "paso del Avestruz" hacia el poniente y el septentrión. Hacia el norte la senda baqueana corría por el oriente de la laguna Blanca rumbo del norte cruzando el río Gallegos por el "paso de los Robles" que permitía acceder al distrito de "Los Morros", preferido por sus atractivos y sus recursos cinegéticos. Por allí, otra vez hacia el norte se cruzaba la "Cordillera Chica" (Meseta Latorre posteriormente) que franqueaba el ingreso al que sería afamado distrito de los caballos baguales (Última Esperanza) y traspuesta la sierra homónima se alcanzaban los atractivos campos del sudoeste del lago Santa Cruz. La senda de Palomares que arrancaba desde Cabo Negro, se confundía en parte con la ruta de las vaquerías y permitía acceder a los campos litorales del mar de Skyring donde se descubrieron vetas carboníferas, tal como había acontecido en la zona de Mina Rica (Brunswick). Por el oriente de las pampas la ruta de los baqueanos seguía los viejos senderos tehuelches y pasaba por "los Tres Chorrillos", Namer y Ciaike y seguía por las formaciones volcánicas de "La Portada" hacia el valle inferior y estuario del Gallegos. El "camino de los indios" conducía a los baqueanos y cazadores y traficantes a lo largo de la costa nororiental del estrecho de Magallanes pasando por "Osiaba" (Oazy Harbour), "Susanacó" (Susannah Cove) y Kolkaike, hasta las vegas de Kemerokaik (Kimire Aike) en el distrito de la Primera Angostura (Martinic, 1979). Por la costa atlántica la senda baqueana siguió el sendero de los aónikenk utilizado por estos en su trashumante movimiento tradicional nortesur y viceversa desde el estuario del río Santa Cruz hasta el litoral del Estrecho, distrito de sus campamentos de invernada y con los mejores campos de caza. Esta ruta indígena más que secular se prolongó hasta el istmo de Brunswick por la costa oriental de la península homónima, pasando por Cabo Negro y Koikash Aiken hasta llegar a punta Santa Ana y la bahía de San Juan una vez que hacia los años de 1820 y 30 la relación de los indígenas con los navegantes de paso se hizo frecuente.

La secuencia toponímica precedente basta por sí sola para apreciar y poner de relieve el aporte de los baqueanos como modestos peones del progreso, pues a sus senderos, a las rastrilladas de sus tropillas, siguieron sucesivamente con el andar del tiempo las rutas más estables de las cabalgaduras y carretas de los colonizadores, origen a su vez de los primeros precarios caminos vecinales y territoriales. Sobre esas mismas huellas de los viejos senderos indígena-baqueanos pudo estructurarse en buena medida el moderno sistema vial del nororiente magallánico y del sur santacruceño.

Los baqueanos, por fin, descubrieron $y$ dieron a conocer terrenos de pastoreo y aguadas, manifestaciones minerales (carboníferas y auríferas) y proporcionaron los primeros datos fiables sobre los recursos naturales en general que permitirian el ulterior desarrollo de la explotación económica territorial. Con un acervo tan rico de conocimiento acumulado por la experiencia aventurera devinieron auxiliares e informantes inestimables 
de exploradores y viajeros científicos. Este fue el gran aporte de esos atrevidos y solitarios que por lo mismo que fue valioso e imprescindible en su hora, ha hecho que su faena sea recordada como genuinamente pionera y provechosa (Martinic, 1979) 22

Aunque contemporáneos y menos importantes a nuestro juicio, los otros protagonistas del fenómeno del progresivo conocimiento geográfico fueron los cazadores y los traficantes, debiéndose dejar en claro que baqueanos $y$ cazadores no siempre fueron oficios diferentes pues en ocasiones un individuo podía ser lo uno o lo otro y no pocas veces, incluso, lo uno y lo otro; por lo visto debió ser, en algunos casos, cosa de oportunidad. En efecto, sin descartarse la posibilidad de un plan de acción previo a la salida de la colonia de Punta Arenas, la abundancia de fauna (avestruces y guanacos principalmente) en sectores por los que transcurría el recorrido, o la presencia de indígenas resultaba determinante para cada opción. En cualquier caso, debe quedar en claro que los primeros, los baqueanos, fueron contados sumando apenas una veintena según nuestras compulsas en un lapso de más de dos décadas; en cambio sí fueron más numerosos los cazadores y muchos los traficantes ${ }^{23}$.

Las actividades de caza y de intercambio con los indígenas parecen haber llegado a su apogeo al promediar los años de 1870 dada la importante participación de algunos de sus productos (pieles de guanaco y plumas de avestruz) en la composición de las exportaciones de la colonia magallánica. Considerados los antecedentes disponibles para el decenio 1869-79 las cifras para el total del comercio de exportación pasaron de $\$ 19.299$ a $\$ 151.171$ para $1875-76^{24}$. Del mismo modo se elevó notoriamente la internación

22 La persistencia de la toponimia debida al paso de los baqueanos, que supera la referencia entregada, conforma la mejor prueba de la aceptación por la comunidad habitante a la actividad descrita y un homenaje permanente en su recuerdo.

23 El censo de población efectuado en la colonia el 16 de diciembre de 1878 por orden del gobernador Carlos Wood (1.174 habitantes; 674 hombre y 500 mujeres), incluyó la ocupación de los censados que, en lo que interesa, registró 8 campañistas (baqueanos) y 29 traficantes con los indios, datos que sólo deben ser tomados como referencia pues no excluye la posibilidad de que otros 33 que se registraron como comerciantes (de $1^{\mathrm{a}}$., $2^{\mathrm{a}}$. y $3^{\mathrm{a}}$. Clase) pudieran de bebidas alcohólicas que era el principal medio de pago a los indígenas, rubro que sólo en 1870 había alcanzado a 172.000 litros. La significación de ese intercambio con los aónikenk está dada no sólo por los datos consignados en los informes coloniales, sino también por las noticias proporcionadas por exploradores y viajeros para el veinteno (1870-1890), tales como Rogers, Beerbohm, Moyano, del Castillo, Bertrand y Greenwood, quienes mencionan la presencia frecuente de los comerciantes de la colonia de Punta Arenas en los aduares indígenas y que empleaban en sus transacciones aguardiente de la peor clase y que no obstante era cotizado por los naturales como la mejor moneda de intercambio mercantil. El consumo alcohólico, excesivo y pernicioso, influiría de manera determinante en la decadencia étnica ${ }^{25}$ (Fig. 2).

\section{c) Exploradores y viajeros foráneos}

El tercer grupo protagónico de la aventura del conocimiento geográfico en consideración estuvo conformado por gente extraña al territorio y cuya presencia histórica obedeció tanto al interés por disponer de información sobre un mundo natural ignoto y salvaje, amén de prístino y exótico que era propio de la gente culta de la sociedad occidental décimonónica, como a encargos especiales de exploración por entidades académicas o por los gobiernos de Chile y Argentina en tanto que interesados en la jurisdicción sobre la región meridional de América, o, de modo excepcional, a la satisfacción de una exigencia motivada por una necesidad condicionada por las circunstancias. Esto explica porqué históricamente el grupo protagonista de esta fase de la aventura del conocimiento geográfico estuvo integrado por un

practicar el comercio con los indios de las pampas siquiera de modo ocasional. En (Of. 28 de 11 de enero de 1879, en volumen Colonización de Magallanes 1879, Archivo Ministerio de Relaciones Exteriores, Santiago).

24 Cfr. del autor Historia de la Región Magallánica, 1992 (2006) tomo II, cap. VI, pág. 608 (Ediciones de la Univerdad de Magallanes, Punta Arenas). El año comercial para el caso abarcaba el período correspondiente a las memorias gubernativas, esto es, desde mayo de un año hasta abril del siguiente.

25 Véase del autor Los Aónikenk..., citado, capítulos "la afición alcohólica" (pág. 114) y "El ocaso de una etnia" (pág. 169) 
puñado de individuos, inferior aun en número a los baqueanos.

$\mathrm{Su}$ importancia para la historia estuvo precisamente caracterizada y calificada por su condición de gente culta lo que determinó la forma $e$ interés de sus observaciones y registros durante sus excursiones o expediciones, y la manera en que prácticamente la totalidad de ellos los consignaron en relaciones escritas, por lo común en forma de libros o de publicaciones especializadas en lo atingente a la geografía del orbe, unos y otras accesibles al mundo culto. Fue precisamente con estas contribuciones tangibles que la sociedad civilizada de Europa y de América principalmente pudo enterarse acerca de las características y singularidades de territorios remotos y fundar sobre esas nociones nuevos y más completos estudios e investigaciones de interés científico y cultural tanto nacional, en los casos de Chile y Argentina, como universal.

Gracias a la progresiva difusión de estas noticias en los ambientes correspondientes y en la política de los estados nacionales fue posible rectificar nociones erróneas por insuficientes, equivocadas, falsas o antojadizas, vertidas con anterioridad por viajeros de paso. En el caso de que se trata, la Patagonia austral, tales nociones tenían su cabal expresión en las infortunadas y precipitadas consideraciones y reflexiones, no siempre acertadas, derivadas de la excursión practicada por el río Santa Cruz arriba por gente embarcada en el bergantín Beagle mientras el mismo se hallaba en faenas de carena en el estuario fluvial (1833), partida exploradora que integró el entonces joven naturalista inglés Charles Darwin. Su objeto era remontar el curso del gran río y llegar hasta sus orígenes en lo posible pero la navegación mayormente a la sirga fue harto pesada y laboriosa por las condiciones naturales y el intento se abandonó tras una profunda penetración tierra adentro. Las impresiones de Darwin quedaron consignadas en su famoso libro El viaje del Beagle, que a partir de su primera edición en 1845 y sus sucesivas reediciones conformó una de las fuentes más valoradas sobre el famoso periplo náuticocientífico y que, en el caso de que se trata fueron acogidas sin reservas fundadas como estuvieron en una autoridad científica que la ulterior fama del naturalista cimentaría, con un carácter de opiniones incuestionables.

Vale recordar, para probarlo, algunos de sus conceptos anotados en su diario con fecha 22 de abril de 1833: El paisaje sigue presentando el mismo escaso interés. La semejanza absoluta de los productos de toda la Patagonia constituye uno de sus caracteres más salientes. Las llanuras guijarrosas, áridas, llevan siempre las mismas plantas desmedradas; en todos los valles crecen los mismos matorrales espinosos. Por doquiera vemos los mismos pájaros, iguales insectos. Apenas si un tinte verde más marcado dibuja las orillas del río y de los límpidos arroyuelos que vienen a verterse en su seno. La esterilidad se extiende como verdadera maldición sobre todo este país, y hasta la misma agua, corriendo por un lecho de guijarros, parece participar de esta maldición ${ }^{26}$.

Las frases finales de esta descripción extraídas unas y otra de su contexto (con lo que quienes así hicieron parecieron no prestar la debida atención a otras menciones del libro donde el juicio es diferente), adquirieron en su difusión el carácter de una sentencia condenatoria inapelable vulgarizada en la manida frase "La Patagonia es un territorio bueno para nada" que tanta difusión tendría en el ambiente oficial chileno de los años 1870 y 1880 y con lamentables consecuencias, como se verá.

Superar una visión tan injusta con una noción más equitativa acerca de la naturaleza y la geografía afectadas por ese duro juicio tomaría mucho, muchísimo tiempo de sostenido esfuerzo y al mismo contribuirían a contar de 1871 las informaciones suministradas por otros exploradores y viajeros.

Explicado así el porqué y los resultados proficuos de sus incursiones tierra adentro en la parte sudoriental de la Patagonia, cabe una mención a quienes fueron los protagonistas de esta siguiente, superior y necesaria fase del proceso del conocimiento geográfico. Estos fueron según el orden cronológico de su arribo al territorio George Ch. Musters (1869), Hilaire Bouquet (1874), Ralph Williams (1874), químico francés incógnito (1875) y Evelyn Ellis (1877), Juan Tomás Rogers (1877, 1879), Enrique

26 El viaje del Beagle (Editorial Labor S.A., Barcelona 1984) pág. 212. Lo destacado es nuestro. 


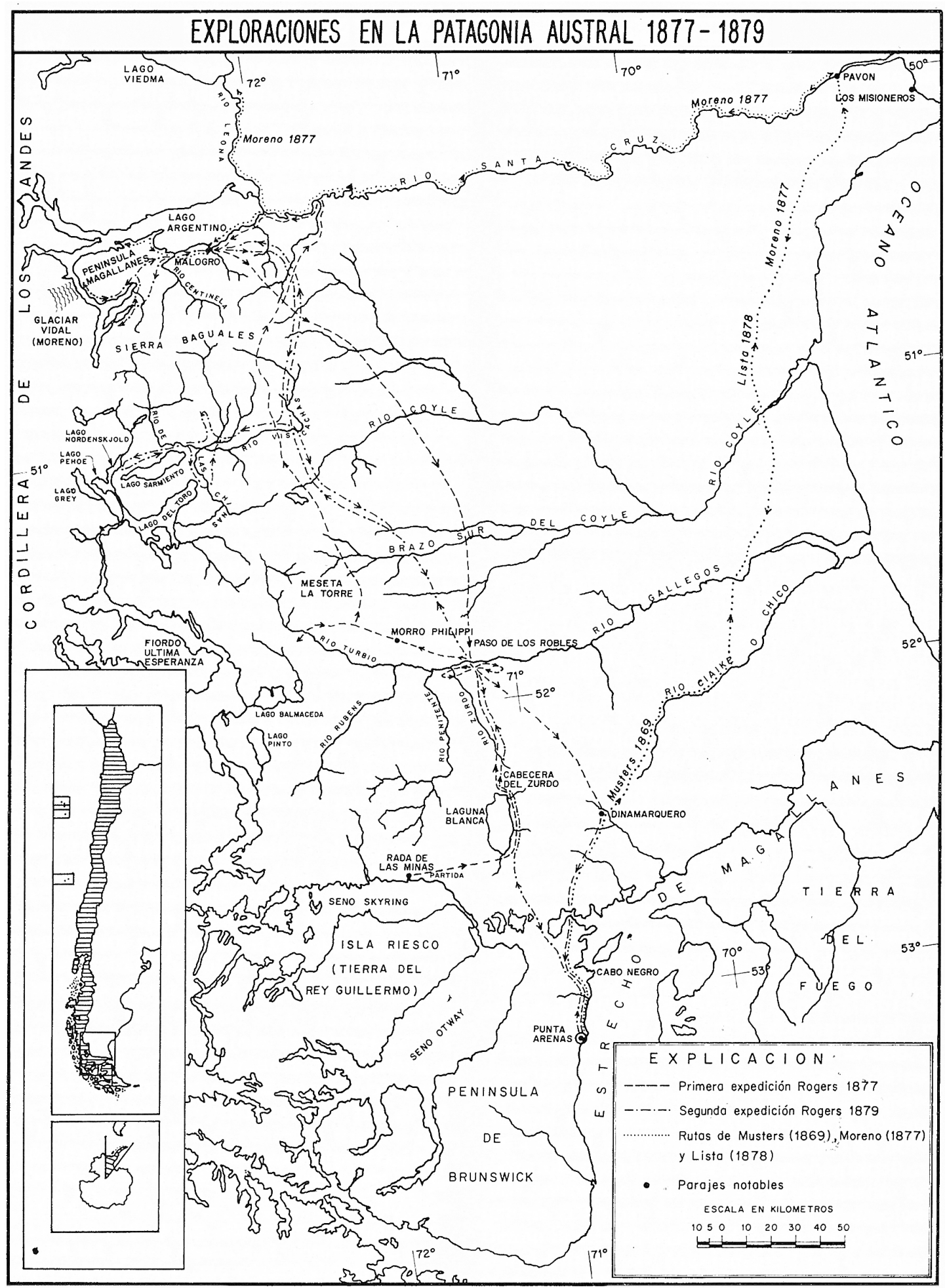

Fig. 2 Exploraciones en la Patagonia Austral 1877-1879. Modificado de Martinic (1977, p. 75) 
Tabla 1. Viajeros y exploradores de la Patagonia Sudoriental 1869-1900.

\begin{tabular}{lccclc}
\hline Nombre & Año & Calidad & Trayectoria & Distrito recorrido & Primera relación \\
\hline George Ch. Musters & 1869 & Viajero & 1 & Oriental & 1871 \\
Hilaire Bouquet & 1874 & Viajero & & Central/Occidental/Oriental & 1875 \\
Ralph Williams & 1874 & Viajero & 1 & Oriental/Central & 1913 \\
Químico Francés (N.N.) & 1875 & Viajero & 1 & Oriental & 1875 \\
Evelyn Ellis & 1877 & Viajero & 1 & Oriental/Noroccidental & ¿ \\
Juan T. Rogers & 1877 & Explorador & 2 & Central/Occidental & 1879 \\
Enrique Ibar Sierra & 1877 & Explorador & 2 & Central/Occidental & 1879 \\
Francisco P. Moreno & 1877 & Explorador & & Noroccidental/Oriental & 1879 \\
Julius Beerbohm & 1877 & Viajero & 1 & Oriental & 1878 \\
Ramón Lista & 1878 & Explorador & 1 & Oriental & 1880 \\
Juan T. Rogers & 1879 & Explorador & & Noroccidental/Central & 1880 \\
Florence Dixie & 1879 & Viajera & 2 & Central/Sur/Occidental & 1880 \\
Gustav Steinmann & 1882 & Explorador & 2 & Central/Sur/Occidental & 1883 \\
Giovanni Roncagli & 1882 & Viajero & 1 & Oriental & 1883 \\
Carlos M. Moyano & 1882 & Explorador & & Oriental/Occidental & 1887 \\
Alejandro Bertrand & 1885 & Explorador & & Central/Sur/Oriental & 1885 \\
Agustín del Castillo & 1887 & Explorador & & Occidental & 1887 \\
Ramón Serrano & 1889 & Explorador & 3 & Occidental & ¿? \\
Ramón Lista & $1890-92$ & Explorador & & Noroccidental & 1896 \\
Otto Nordenskjold & 1896 & Explorador & 3 & Noroccidental & 1897 \\
\hline
\end{tabular}

1. Senda indígena (Aónikenk)

2. Rutas baqueanos

3. Rutas nuevas

Ibar Sierra (1877), Francisco P. Moreno (1877), Julius Beerbohm (1877), Ramón Lista (1878, 1890-92), Florence Dixie (1879), Gustav Steinmann (1882), Giovanni Roncagli (1883), Carlos M. Moyano (1883), Alejandro Bertrand (1885), Agustín del Castillo (1887) y Ramón Serrano Montaner (1889). Esta nómina entera hasta donde se sabe el elenco de exploradores y viajeros comprendido entre 1869 y 1890 . La Tabla 1 resume sus respectivas calidades (explorador o viajero) y trayectorias, así como época de la publicación de sus viajes.

Aunque genéricamente todos ellos fueron viajeros, nos ha parecido conveniente categorizarlos según si sus recorridos los hicieron cumpliendo una misión específica como fue el caso de los exploradores

27 De la nómina consignada únicamente se ha excluido al antiguo gobernador de la Colonia de Magallanes Diego Dublé Almeida que en 1879 realizó una comisión oficial entre Punta Arenas y los Misioneros (estuario del río Santa Cruz) para verificar la ocupación del lugar por fuerzas para observar y describir la geografía incógnita, o por el mero placer de la aventura en tierras exóticas por razón de goce estético o espiritual, el ánimo deportivo -en el concepto del sport de la época victoriana que tenía la gente británica de buen nivel social-, la práctica de la caza o un poco de todo ello. Así Rogers, Ibar, Moreno, Moyano, Lista, Steinmann, Bertrand, del Castillo y Serrano deben ser vistos y reconocidos como verdaderos "exploradores" y los demás como simples visitantes viajeros. La excepción fue Beerbohm, cuyo trayecto por el territorio fue impuesto por la necesidad de llegar a Punta Arenas para tomar alli un vapor de la carrera de ultramar ${ }^{27}$. Gustav Steinmann si bien revista en el primer grupo difiere de los otros en cuanto estos fueron observadores generalistas

argentinas y por la irrelevancia de su viaje en el aspecto que interesa. Sus incidencias por otra parte fueron recogidas en un diario de viaje que fue publicado recién sesenta años después, en 1938, en la Revista Chilena de Historia y Geografía. 
de la naturaleza, mientras que él fue el primero que realizó estudios especializados en geología.

Si bien estas expediciones conformaron en su conjunto un fenómeno de prolongado curso extendido hasta el fin del siglo XIX, lo dividimos en dos etapas para los efectos de la consideración que hacemos; una primera extendida sólo hasta 1880 para evaluar especialmente la información disponible para 1881, época en que los gobiernos de Chile y Argentina, países que se disputaban el dominio del territorio austral, acordaron su reparto jurisdiccional; y otra desde el último año hasta 1900 año con el que en nuestros estudios historiográficos hemos dado por concluido el proceso inicial del poblamiento territorial en el distrito de las pampas.

\section{d) Colonos pastoriles pioneros}

Al promediar los años de 1870 la afirmación del establecimiento de Punta Arenas como colonia propiamente tal era cosa evidente: su población crecía y se diversificaba además, principalmente por la inmigración europea; su precaria producción económica se veía más sólida e insinuaba una nueva envergadura sin embargo de estar referida a las producciones primarias de una situación de frontera (pieles, plumas, minerales y maderas); se advertían por fin los primeros signos de alguna actividad innovativa que permitía superar las fases elementales de explotación. En su procura, las miradas de cuantos así pensaban pasaron a fijarse sobre las comarcas distantes de Punta Arenas cuyos campos y recursos naturales parecían cada vez más atractivos e interesantes. Quizá los animara la iniciativa del gobernador Oscar Viel que en 1873 y preocupado por el adelanto del establecimiento a su cargo decidió crear la "Colonia Presidente Errázuriz" en el sector de Agua Fresca, al sur de Punta Arenas, para lo que promovió la contratación de inmigrantes suizos agricultores, que fueron arribando entre 1876 y 1878. También pudo influir otra iniciativa de la época y la misma especie, la "Colonia Franco-Chilena del Sur", ideada por inmigrantes franceses para explotar las pasturas y otros recursos del noroeste de Punta Arenas (comarcas de las vaquerías) y que fue iniciada en 1875 en la zona de Mina Rica, aunque de efímera existencia por un equivocado planteamiento de explotación carbonífera y maderera. Pero, más pudo animar a cuantos deseaban realizar algún emprendimiento novedoso las noticias que periódicamente traían a Punta Arenas los que retornaban de las pampas, baqueanos, cazadores y traficantes, y que daban cuenta de sectores que abundaban en recursos como los que propiamente interesaban para la crianza de ganado mayor.

De ese modo la autoridad colonial comenzó a recibir sucesivas solicitudes de ocupación de terrenos en diferentes lugares del extenso ámbito septentrional de Punta Arenas. Deben mencionarse como las primeras las peticiones de Hilaire Bouquet y Jules Fluchart, a nombre de la mencionada Colonia Franco-Chilena del Sur (20.000 hectáreas en la Vaquería del Norte) y del británico James J. Gale (100.000 hectáreas en San Gregorio). Aunque estas no llegaron a hacerse efectivas, quizá por ambiciosas de momento, si lo hicieron otros peticionarios como Juan de Dios Gallegos, antiguo oficial de la guarnición y, Vital Díaz, integrante del grupo de inmigrantes de Chiloé venidos con Viel, que obtuvieron campos para establecer pequeñas haciendas de crianza en Cabo Negro y Palomares (zona del canal Fitz Roy), respectivamente en 1875.

En 1876 el español José Manzano se instaló en un paraje próximo a la laguna Blanca y que desde entonces comenzó a ser nombrado como "la carpa de Manzano" (actualmente Carpa Manzano) con una crianza de cerdos y aves. Por ese mismo tiempo el alemán Julius Haase inició la explotación de un yacimiento de carbón descubierto años antes por Santiago Zamora en el sector de Río Verde, costa del mar de Skyring (Mina Marta). Tiempo después el colono suizo Emilio Bays adquirió los derechos de Gallegos e impulsó la crianza pecuaria en Cabo Negro, abriendo, asimismo, el primer aunque inicialmente primario hotel de campaña para brindar hospedaje a los viajeros.

Pero, aunque incipiente y modesta, esta fase expansiva del ecúmene colonial cobró un mayor vigor luego que otro inmigrante de años recientes, el inglés Henry L. Reynard tuvo la iniciativa feliz de criar ovejas en la estepa de manera extensiva según se venía haciendo, y con gran éxito, en las Islas Falkland (Malvinas) desde 1840. Hasta entonces, debe aclararse, se habían tenido ovejas en Punta Arenas, traídas originariamente desde Chiloé, pero únicamente para la crianza doméstica y el consumo alimentario de la población. La idea innovadora de 
Reynard, en cambio, apuntaba a la producción de lana para la exportación al Reino Unido o a otros países europeos. Interesó para ello al gobernador Dublé Almeida con quién viajó a Puerto Stanley en 1876 a bordo de la corbeta nacional Chacabuco y alli pudo adquirir un rebaño de 300 ovejas que a su retorno puso a pastar en la isla Isabel (estrecho de Magallanes al noreste de Punta Arenas), que le fue expresamente cedida por la autoridad para practicar un ensayo de aclimatación. La experiencia resultó exitosa al cabo de un año, por lo que el animoso inglés decidió hacer una nueva importación de animales desde el archipiélago atlántico. Su auspiciosa experiencia animó a otros como el colono nacional Cruz Daniel Ramírez y los inmigrantes franceses Marius Andrieu y Francisco Roig para pedir otras concesiones de terrenos pastoriles, aquél en la isla Magdalena y éstos en la costa de la bahía de San Gregorio (1878), que por cierto obtuvieron dada la comprensión manifestada por el nuevo gobernador Carlos Wood para la más pronta recuperación de la colonia magallánica luego del trágico suceso conocido como "motín de los artilleros" (noviembre de 1877).

Si Ramírez fracasó con su propio ensayo, el de Andrieu y Roig resultó exitoso tanto que para enero de 1879 poseían en San Gregorio una pequeña estancia de crianza ovina con 700 ovejas y una instalación compuesta de cinco casas y un galpón, para cuyo servicio disponían del vaporcito de su propiedad Toro. En su vecindad, algunos kilómetros al oeste, junto a la bahía Oazy, Henry L. Reynard hacía surgir un nuevo y mayor establecimiento de crianza y, según parece animaba al apreciado médico de la colonia, Dr. Thomas Fenton a hacer otro tanto en campos vecinos del occidente, sector de la laguna Casimiro, como en efecto sucedería a poco andar. Mientras así ocurría, el antiguo herrero Guillermo Bloom, solicitaba y obtenía otro campo en la misma costa del Estrecho, entre las ocupaciones de Andrieu \& Roig y Reynard. No demoraría en hacer otro tanto el portugués José Nogueira, quien para entonces poseía una pequeña fortuna hecha sobre la base del negocio de la caza y exportación de pieles de lobos marinos, del ejercicio del comercio en general y

28 Para 1880 la dotación ovina se calculaba en 3.000 cabezas, cantidad de momento sorprendente que al concluir el siglo alcanzaría el millón de animales, duplicarse dos del fletamento de embarcaciones, principalmente. Nogueira puso sus ojos en los excelentes campos del istmo de Brunswick, al norte del río del Pescado, en los que a poco andar iniciaría la que sería su gran estancia "Peckett Harbour". Esos asentamientos de colonización pionera además de marcar el primer jalón de la expansión del ecúmene colonial tierra adentro, tenían la indudable ventaja de ser ocupaciones litorales, lo que les aseguraba la comunicación marítima expedita con Punta Arenas, para todos los efectos.

De la manera resumida, unos tras otros se empeñaron en impulsar sus emprendimientos, unos, los más, saliendo avante y otros, los menos, fracasando. Comprometiendo el escaso capital que podía haberse acumulado en los años precedentes, mucho y variado trabajo de diversa índole y una dosis increíble de tenacidad y coraje para enfrentar sacrificios y contrariedades, la faena pobladora pastoril comenzaba así a cobrar algún relieve, harto modesto todavía, pero ciertamente promisor de cara al porvenir ${ }^{28}$. La colonia de Magallanes comenzaba a redimirse de su triste fama y se encaminaba por auspicioso rumbo al concluir la agitada década de 1870 .

\section{e) La noción del hinterland colonial}

Había bastado en la práctica el transcurso de una década, a partir de 1870, para que la situación del conocimiento territorial cambiara visiblemente. En efecto, lo que hasta entonces era un asiento poblado de modo permanente en la costa oriental de Brunswick que apenas trascendía con su influencia los bien acotados lindes comarcales, para $1880 \mathrm{al}$ cabo de diez años de iniciada la penetración sobre la que se ha dado cuenta, ofrecía a propios y extraños la noción de ser la "Colonia de Magallanes" mucho más que un poblado modesto como que incluía un vasto hinterland conformado por su vasto entorno que iba recibiendo su influencia y sujetándose a su jurisdicción.

Semejante noción para el historiador actual fluye de la revisión de los escritos de la época debidos a testigos que dejaron impresiones sobre lo visto u observado que, consideradas y evaluadas

décadas después y triplicarse pasada la mitad del siglo XX y ello únicamente sobre el territorio que pasaría a ser de jurisdicción exclusiva de Chile en 1881. 
en su conjunto y contexto permiten concluir, como se hace. El ecúmene magallánico se había ampliado y se afirmaba extendiéndose por el norte y el noroeste de Punta Arenas hasta los límites que la naturaleza geográfica parecía haber señalado con claridad desde tiempos inmemoriales y que la población civilizada incorporada había ido asumiendo paulatinamente: hacia el septentrión el río Santa Cruz y por el oriente el océano Atlántico sur. Es un amplio cuadrilátero geográfico que va desde los Andes al Atlántico, y desde el río Santa Cruz al estrecho de Magallanes que abarca unos $75.000 \mathrm{~km}^{2}$ aproximadamente.

Esas impresiones, que hay que saber leer sobre todo cuando son implícitas o sugeridas, pueden encontrarse en los textos de Moreno, Rogers, Lista, Beerbohm, Dixie y Greenwood. El primero, arquetipo de los que al revés de Darwin recorrió observando con sensatez el vastísimo territorio patagónico por sus diversos distritos, viajó por el que nos ocupa (curso del río Santa Cruz y sectores de sus nacientes incluidos los lagos Argentino y Viedma, y los terrenos litorales del sureste de Santa Cruz y noroeste del estrecho de Magallanes en 1876-77), registrando con la acucia de un verdadero notario de la naturaleza todo lo referido a ella y a la presencia humana indígena o civilizada. Pero el testigo de aparición impresa más reciente, William $\mathrm{H}$. Greenwood, con sus recuerdos de tantos años de andanzas y aventuras por un territorio que conoció en profundidad y que lo subyugó ${ }^{30}$, es quien abunda en noticias específicas sobre la presencia de la gente de Punta Arenas tierra adentro, con la sugerencia implícita y reiterada de una sujeción factual a la jurisdicción de ese establecimiento.

En verdad, para esos años de tanto ir y volver de baqueanos, traficantes, viajeros y exploradores, la vinculación entre Punta Arenas y su hinterland era cosa patente. El poblado del Estrecho con su pequeña y activa comunidad era tanto la puerta de entrada al y la de salida del espacio sudpatagónico, como el repositorio de las noticias que al mismo atañían y el depósito de los productos que desde él procedían. Ciertamente no se requería de gran perspicacia por parte de quien arribado a ese

30 Op. cit. Tocante a los escritos de Moreno y Lista, véanse respectivamente, sus libros Viaje a la Patagonia Austral 1876-1877 (Solar-Hachette, Buenos Aires 1964, págs. remoto paraje austral del continente americano, para advertir a poco de permanecer en él que en el mismo y en su enorme territorio interior dependiente había una potencialidad latente de desarrollo pronta a manifestarse.

\section{f) El acuerdo jurisdiccional y el reparto}

del territorio entre Chile y Argentina

Al promediar la década de 1865 la situación jurisdiccional de la Patagonia se mantenía como estaba una veintena de años antes cuando Chile se había establecido en el litoral del Estrecho reivindicando la antigua dependencia que el mismo y su extenso territorio habían tenido de la gobernación homónima en el contexto del imperio español en América. Ello había cobrado forma con la posesión efectiva y con la instalación de una guardia militar de soberanía en la punta de Santa Ana (1843) para hacer de la misma la base de una ocupación colonizadora, acto seguido por el tardío reclamo del gobierno de Buenos Aires (1847), con lo que quedó trabada una controversia entre los dos estados que no cambió con el tratado de 1856, según se ha mencionado, por el que ambas naciones se reconocían recíprocamente las jurisdicciones territoriales que tenían al tiempo de independizarse de España, a partir de 1810, y habían acordado su resolución pacífica mediante un acuerdo ad hoc o, en su defecto, por la vía del arbitraje de una nación amiga. Ese tranquilo lapso había sido aprovechado por una y otra partes para llevar adelante investigaciones en los archivos coloniales en búsqueda de títulos que ampararan sus correspondientes pretensiones al territorio patagónico. Pero esa situación comenzó a cambiar una vez que por una parte el gobierno argentino favoreció el establecimiento de colonos galeses en la zona del valle inferior del río Chubut (Patagonia central atlántica), con reconocimiento de su soberanía, y coetáneamente, por otra, había estimulado y apoyado las actividades de Luis Piedra Buena con miras al establecimiento de una colonia argentina en la bahía de San Gregorio (estrecho de Magallanes) para afirmar así su pretensión jurisdiccional y neutralizar la presencia chilena en

397 a 407); y Mis exploraciones y descubrimientos en la Patagonia (1877-1880 (Marymar Ediciones, Buenos Aires 1975, págs. 58 a 75). 
Punta Arenas.

En el curso de esa nueva situación el gobierno chileno acreditó a José Victorino Lastarria como su representante diplomático ante el gobierno del Plata, quien entre sus misiones llevaba el encargo de gestionar un arreglo en la controversia de marras. Este enviado, obviando las instrucciones que le prescribían la búsqueda de una transacción equitativa y razonable, propuso de motu propio a la cancillería argentina un arreglo que importaba la cesión de casi la totalidad de la Patagonia oriental, más parte del Estrecho y de la Tierra del Fuego, iniciativa desatinada que provocó el disgusto del gobierno de Chile y que sin embargo de su generosidad en términos territoriales fue rechazada por el de Argentina, con el consiguiente fracaso en su misión diplomática. Así la cuestión amén de permanecer insoluta comenzó a agriarse y enturbiarse ${ }^{30}$.

Importa recordar que el fallido agente diplomático, con una porfía digna de mejor causa, todavía insistió ante el gobierno de Santiago alegando que sus términos no podían haber sido otros...porque no son sostenibles nuestros títulos a la Patagonia, y aunque lo fueran, no debemos hacernos ilusiones creyendo que aquella extensión sea otra cosa que tierras primitivas, incultivables y de todo punto de vista ingrata a los hábitos y aspiraciones de la industria ${ }^{31}$. Esa tan ligera como lamentable opinión de un literato que se las daba de conocedor de la geografía, además de conformar un desabrido eco de la opinión de

30 La cuestión de límites chileno argentina ha sido materia de una sostenida preocupación historiográfica, iniciada en Chile con el libro de Miguel Luis Amunátegui (1855) y en Argentina con los trabajos de Pedro de Angelis (1852) y Dalmacio Vélez Sarsfield (1853), y que ha llegado hasta nuestros días. La bibliografía es abundantísima en ambos países pues no se limita a la cuestión original que, en lo general, fue resuelta por el tratado de 1881, pues incluye sus secuelas originadas en la ambigua redacción de sus disposiciones esenciales que, a su tiempo, fueron materia de enojosas situaciones y arduas negociaciones concluidas con los laudos arbitrales de 1902, 1966 y 1977, hasta el Tratado de Paz y Amistad de 1984 que puso término definitivo a la fase más prolongada de la más que secular controversia, la del dominio de las islas del sur del canal Beagle. Sólo como mera referencia informativa para el lector valga la mención de dos obras que sin ser equivalentes han buscado ser totalizadoras: Historia de las fronteras de Chile. Los tratados de límites con Argentina, de Guillermo Lagos Carmona (Editorial Andrés Bello 1980 (1966), Santiago; y Límites y Fronteras de la Argentina
Darwin ya mencionada, iniciaría una retahila de descalificaciones acerca de la importancia de la Patagonia cuyo clímax se alcanzaría después con Benjamín Vicuña Mackenna, quizá el más contumaz negador del valor de ese territorio.

La tentativa de Piedra Buena de ocupación en San Gregorio fue renovada en 1869 y volvió a fracasar, esta vez por la vigilante cautela del gobernador Viel, con quien, cabe destacarlo, la actitud chilena de defensa de sus derechos territoriales australes se hizo más evidente y firme sostenida como hubo de estar por la postura del ministro de Relaciones Exteriores Adolfo Ibáñez respecto de la bondad y legitimidad de los títulos defendidos por Chile. Fue en ese contexto que Ibáñez, tras dos otras propuestas transaccionales que nuevamente fueron rechazadas por el gobierno argentino, formuló su declaración de 25 de junio de 1873 por la que se hizo saber al mismo y a terceras naciones que Chile no consentiría acto alguno que amenguase su soberanía en toda la extensión de los territorios de cuya actual y pacífica situación se encuentra y que tiene su limite actual en el río Santa $\mathrm{Cruz}^{32}$.

Abundando sobre el punto, pensamos que si para los gobernantes chilenos estuvo claro desde un principio que el objetivo geográfico de su dominio (o aspiración jurisdiccional) era el estrecho de Magallanes en tanto que vía marítima interoceánica, no fue así respecto de su extensión tierra adentro más allá de sus litorales norte y sur (o nororiental y sudoriental para mayor precisión).

por Raúl C. Rey Balmaceda (Oikos, Buenos Aires 1979). Las distintas visiones historiográficas nacionales, por otra parte, han sido bien expuestas y analizadas por Pablo Lacoste en su equilibrado y bien logrado libro La imagen del otro en las relaciones de la Argentina con Chile (1534 -2000) (Fondo de Cultura Económica-Universidad de Santiago de Chile, Buenos Aires 2003). Hacemos también mención a nuestros propios estudios como son Presencia de Chile en la Patagonia Austral 1843-1879, mencionado antes, Historia de la Región Magallánica (Edición del autor, Santiago 1992 y reedición de la Universidad de Magallanes en 2006, en este caso el tomo IV) e igualmente De la Trapananda al Áysen (Pehuén Editores 2005 y Fundación Río Baker 2014, Santiago).

31 Francisco A. Encina, La cuestión de limites entre Chile y la Argentina desde la Independencia hasta el tratado de 1881 (Editorial Nascimento, Santiago 1959) pág. 25).

32 Memoria de Relaciones Exteriores y Colonización 1874, citado por el autor en Presencia de Chile..., mencionada, pág. 161. 
El asunto en lo que se refería a la parte norte debió comenzar a preocupar una vez que la Confederación Argentina reclamó en 1847 por la posesión chilena de 1843 y, con mayor razón, a contar de 1865-70 que fue cuando el país del Plata explicitó sus propias pretensiones que, a lo menos, incluían la mitad del litoral norte del Estrecho. 1870 pasó a ser así para cuantos se preocupaban en Chile por la materia el tiempo de dirigir la mirada tierra adentro en la búsqueda de un "limite natural" para el que debía entenderse como territorio del gran canal y, por consecuencia, como objeto de su reclamo por Chile. Entonces fue que, sobre la base de lo escasamente conocido con antelación y más una vez que a partir del año indicado comenzaron las incursiones de la gente de Punta Arenas hacia su hinterland septentrional, surgieron o mejor dicho se hicieron visibles los deslindes naturales conformados por los ríos Gallegos y Santa Cruz. Este último en particular por su amplitud, longitud y enorme caudal y por su morfológicamente bien definido valle fluvial, a diferencia del primer curso mencionado, aparece a la vista de cualquier observador como un claro límite natural, útil por lo mismo para servir como un límite más aceptable que una traza artificial y convencional. Bien podía aprovecharse en consecuencia, como se hizo, para hacer del curso del río Santa Cruz la línea de máxima aspiración jurisdiccional chilena en la zona sudoriental de la Patagonia atlántica. Pensamos que, sin hacer juicio sobre las razones que pudo tenerse para abandonar de facto la reclamación sobre el resto del territorio situado al norte del mencionado curso fluvial, por no ser del caso, la declaración transcrita reflejaba por una parte la convicción cada vez más firme de los que se interesaban en el asunto, en cuanto que el Santa Cruz representaba de un modo clarísimo una suerte de división natural entre los espacios central y meridional de la Patagonia, haciendo del ámbito comprendido entre aquel río y el estrecho de Magallanes un tributario del territorio mayor cuyo eje geográfico es el gran canal interoceánico; $y$, por otra, que la circunstancia de ser ese mismo espacio el hinterland igualmente natural de la colonia de Punta Arenas. De allí, entonces, que afirmar esa presencia estimulándola con acciones de soberanía pareció ser cosa buena y necesaria, como lo fue en la práctica hasta 1875 sin embargo de los fallos o debilidades constatados en la política así sostenida.

Por contra, la actitud argentina, cada vez menos conciliadora y más firme y clara en la defensa de sus propias pretensiones movió otra vez al gobierno de Chile en 1876 a intentar la búsqueda de un acuerdo. La coyuntura la brindó la renuncia de Ibáñez a su cargo ministerial motivada por la falta de respaldo a su política cada vez más cuestionada en el entorno político del Presidente Federico Errázuriz Zañartu. Para ello se encomendó a Diego Barros Arana, intelectual de prestigio y con relaciones familiares en Buenos Aires, la gestión de procura de un arreglo amistoso. Este diplomático de circunstancia en su tarea que no fue fácil ni grata extremó inclusive los términos de sus instrucciones para conseguir la anhelada conciliación, pues aunque la inició reiterando la línea del río Santa Cruz para la partición jurisdiccional, al obtener un rechazo, como ocurrió, planteó en subsidio otra situada más al sur esta vez haciéndola coincidir con los $51^{\circ} 35^{\prime}$ de latitud sur, esto es, desde el estuario del río Gallegos hasta la cordillera de los Andes. Esta propuesta, por demás generosa y conciliadora a nuestro juicio, fue otra vez desestimada por la cancillería argentina que, a su tiempo, contrapropuso una línea más desfavorable para Chile situándola en los $52^{\circ} 10^{\prime}$ de latitud, con principio en Monte Dinero (litoral del estrecho de Magallanes) para proseguir desde allí al occidente hasta los Andes.

La proposición argentina fue a su vez rechazada por Chile con lo que la misión de Barros Arana se dio por finalizada al advertirse que no había disposición entre las partes para concordar una solución que fuera reciprocamente satisfactoria. La situación que por consecuencia se pasó a vivir en el territorio austral fue un reflejo de ese fracaso diplomático: por parte de Chile, firmeza en el control de la soberanía marítima sudatlántica y retrocesos y reticencias en las acciones de presencia de sus nacionales o de extranjeros bajo su amparo en el territorio sudoriental; por parte de Argentina autorizaciones para la extracción de guano de covaderas al sur del estuario del Santa Cruz y el envío de una fuerza naval al mismo punto que permitió la ocupación de la ribera sur del río (1878), acción que asumió por momentos la condición de virtual casus belli entre los dos 
países, situación que se conjuró con el conocido como Pacto Fierro-Sarratea (por Alejandro Fierro ministro de RR.EE. chileno y Mariano A. de Sarratea, cónsul argentino en Valparaíso que lo negociaron), que en los hechos implicó una nueva cesión en la posición oficial chilena al admitir lo acontecido. Para entonces el gobierno de Santiago y el Congreso -que aprobó el acuerdo con la oposición minoritaria de cuantos habían apoyado y apoyaban los reclamos nacionales en la controversia-, parecían más preocupados por la situación del norte (Antofagasta) que se complicaba por la tensión con Bolivia y que amenazaba con una ruptura. El congreso argentino no prestó su aprobación al acuerdo mencionado y la situación ingresó así en un prolongado statu quo, sin que en el territorio austral ello afectara la dinámica expansiva de Punta Arenas, entonces en sus comienzos.

La ocupación del puerto de Antofagasta por parte de Chile en febrero de 1879, el estado de guerra consiguiente con Bolivia en el que no tardó en verse envuelto el Perú, al que Chile le declaró la guerra al divulgarse la existencia de un pacto secreto del año 1873 entre esa república y Bolivia para atacar al vecino del sur, exigió toda la atención del gobierno y del país que se prepararon para enfrentar la gravísima emergencia.

En esa difícil coyuntura, la Guerra del Pacífico, Argentina que se había mantenido neutral pese a haber sido requerida por los aliados Perú y Bolivia en su hora, intentó todavía un arreglo de la añeja controversia del extremo sur, por cierto a su modo, al proponer el 17 de abril de 1879 un proyecto de transacción que en lo sustancial planteaba una línea divisoria que desde los Andes en latitud aproximada $52^{\circ}$ sur oblicuaba hasta la bahía Oazy en el estrecho de Magallanes, para seguir hacia el sur por el paso Ancho, el paso Boquerón, canal Whiteside y el fiordo del Almirantazgo hasta su fondo, cruzar luego la Tierra del Fuego por su parte más angosta, seguir por el canal Beagle hasta el de Murray hasta alcanzar finalmente el cabo de Hornos. Ello en buenas cuentas significaba que quedaban para Argentina toda la Patagonia oriental, la mitad del Estrecho y casi la totalidad de la Tierra del Fuego incluyendo las islas del sur de la misma al este del canal Murray. Chile recibía la mitad restante del Estrecho con apenas un mínimo territorio al norte de Punta Arenas, más las islas y la parte menor de Tierra del Fuego ubicadas al occidente de la línea propuesta. En la coyuntura en que se hallaba Chile rechazó de plano la proposición, dejando de manifiesto que el dominio completo del Estrecho era una base intransable para un eventual arreglo.

Así se arribó a 1881. Para entonces tanto el cuadro internacional como el territorial patagónico había variado y de modo notorio. Chile seguía en guerra con Perú y Bolivia, aunque el conflicto concluía en su favor con resonantes victorias militares y la ocupación de Lima (enero). Argentina se había mantenido al margen de esa contienda pero había aprovechado bien el tiempo liquidando el antiguo problema indígena de las Pampas y Norpatagonia lo que la había llevado a establecer su soberanía plena sobre esas regiones (Campaña del Desierto), hasta los Andes y el río Negro, quedando así en óptima posición geopolítica de cara al sur. Entonces, el triunfo de Chile en el norte y su poderío militar y naval incuestionable lo dejaron en buena situación como para negociar con tranquilidad la controversia por el dominio de la Patagonia en procura de un acuerdo que satisficiera a las partes.

En el lejano sur, entre tanto, las cosas si no habían cambiado ostensiblemente permitían advertir a simple vista la manifiesta presencia de la gente de Punta Arenas en las zonas de su hinterland, con lo que no habría de transcurrir mucho tiempo antes de que, en los hechos fuera difícil para Argentina revertir esa situación con actividades de ocupación económica cada vez más estables e importantes, buscando, como lo hacía, asegurar para sí la mayor extensión posible del territorio disputado.

Por eso en ese país sus dirigentes y hombres de relieve político, no pocos de ellos con aguda visión de futuro y una razonable comprensión geográfica, entendieron que tal vez ese era el momento para presionar a Chile en busca de un arreglo, sabedores que del otro lado de los Andes había quienes por diferentes motivaciones privilegiaban sobre todo la paz con la nación vecina. Había que aprovechar esa circunstancia. En el esfuerzo, que bien lo valía, participó gente de buena voluntad de las clases dirigentes políticas y de respetables posiciones sociales en procura de una instancia de interlocución que facilitara el 
entendimiento $y$ permitiera encontrar al fin un acuerdo transaccional viable.

Primero intervinieron Mariano de Sarratea y Dalmacio Vélez Sarsfield, aquél ante el gobierno de Santiago y éste ante el de Buenos Aires. Conseguida la apertura anímica necesaria para endilgar por buen rumbo la interlocución, la responsabilidad recayó en Thomas A. Osborn y Thomas O. Osborn, primos hermanos que respectivamente se desempeñaban como ministros (embajadores) de los Estados Unidos de América ante los gobiernos de Chile y de Argentina. Esos fueron los protagonistas aparentes, pues quien movía todos los hilos de la trama era el habilísimo canciller argentino Bernardo de Irigoyen. La negociación se daba, en el caso de Chile porque en lo referido a Argentina no era así, en un ambiente proclive al acuerdo en que lo intransable era el dominio total del estrecho de Magallanes y lo negociable eran los territorios que se sitúan allende sus litorales. Tocante a esta última parte pasó a hacerse evidente la influencia de cuantos habían asumido el oficio de "denostadores de la Patagonia", con el brillante, elocuente y contumaz Benjamín Vicuña Mackenna a la cabeza, cuya opinión era tan respetada en los ambientes político y social santiaguinos, y qué decir en el seno del gobierno presidido por Aníbal Pinto, hombre íntegro y patriota, pero débil e influenciable. Vicuña Mackenna acababa de publicar el año anterior su libro La Patagonia, obra preparada exclusivamente para cuestionar la importancia de ese territorio al que se descalifica, de principio a fin, con los más duros epítetos y cuyos denuestos alcanzaban a cuantos sostenían una opinión diferente a la del autor ${ }^{33}$. Debe suponerse que ese libro fue generosamente distribuido para su lectura por cuantos de algún u otro modo fueron llamados a opinar sobre el serio y trascendente asunto de que se trata.

En ese contexto debió negociarse, a través de los intermediarios Osborn porque entonces ninguna de las partes mantenía ante la otra una representacióndiplomáticaformal.EnBuenosAires, la cancillería a cargo del talentoso Irigoyen se hizo cargo aportando su conocimiento de la cuestión y el

33 Imprenta del Centro Editorial, Santiago 1880.

34 Op. cit., pág. 52. El territorio asignado a Chile comprendió los distritos que denominamos Zona Centro-Oriental Magallánica y Última Esperanza con una superficie estimada caudal de información geográfica que le brindaban sus asesores (el conocimiento de un territorio era una forma primaria o elemental de posesión del mismo y eso lo intuyeron o comprendieron bien desde un principio los exploradores argentinos). En Santiago, Diego Barros Arana ayudó al Presidente Pinto en la negociación y creó en torno a ella la atmósfera adecuada para su éxito, ha escrito Guillermo Lagos Carmona al abordar el asunto, añadiendo que Entre la guerra y la paz, el maestro de juventudes, el historiador y el diplomático, había optado por la paz. Si bien el arreglo amistoso de 1881 entre Argentina y Chile fue una transacción que aseguró para Chile todo el Estrecho de Magallanes, no se le perdonó la pérdida de la Patagonia ${ }^{34}$. Las bases del acuerdo recogidas en un articulado que se tuvo por preciso y claro inicialmente pero que más tarde se entendió como ambiguo, que dio forma al tratado de límites suscrito en Buenos Aires con fecha 23 de julio de 1881. En lo fundamental que interesa a este trabajo, la cordillera de los Andes fue establecida como elemento geográfico para la división de jurisdicciones nacionales hasta el grado $52^{\circ}$ sur, en que se adoptó una línea de compromiso siguiendo el paralelo $52^{\circ} \mathrm{S}$ hasta su intersección con el meridiano $70^{\circ}$ este y desde allí hasta el monte Aymond y luego siempre al oriente, por las alturas locales hasta alcanzar la punta Dungenes. El territorio situado al norte de la misma fue reconocido como argentino y chileno lo fue el ubicado al sur, incluyendo todo el litoral del Estrecho.

Relatado así, de modo sumario, el transcurso del proceso de definición jurisdiccional y el consiguiente reparto territorial, nos parece pertinente hacer algunas reflexiones acerca de cómo pudieron darse las cosas y, en especial, sobre los antecedentes de los que pudieron disponer aquellos hombres públicos a los que correspondió plantear la defensa de los derechos alegados por Chile. Si al fin esta se centró en la conservación del Estrecho para Chile y sobre este punto no cabe abundar por ser algo obvio ${ }^{35}$, es evidente que la discusión estuvo en la extensión de territorio que

en unos $25.000 \mathrm{~km}^{2}$.

35 Véase al respecto nuestro estudio "Estrecho de Magallanes, territorio marítimo chileno", Anales del Instituto de la Patagonia, 12, 7-29, Punta Arenas 1981. 
debía ser entendida como la propia y natural del gran canal para dar un margen de seguridad a ese dominio.

Así y conocidos igualmente la negativa de Argentina para aceptar el curso del río Santa Cruz como divisoria de jurisdicciones y su rechazo a la aceptación de toda presencia chilena en el litoral oriental, nos preguntamos porqué las sucesivas propuestas de arreglo que se hicieron se graficaban con líneas paralelas a la latitud geográfica cada vez más al sur, cuando perfectamente y sin mayor perjuicio para Argentina porque su posición se aceptaba -visto lo mucho que en el hecho esa república iba consiguiendo-, plantearse con una línea de partición oblicua, esto es, por ejemplo, con una diagonal que partiendo del nacimiento del río Santa Cruz en el lago Argentino hubiera seguido en derechura hasta el cabo Vírgenes. Una proposición semejante no habría lesionado la sustancia del reclamo argentino y sí habría resultado más justa y equitativa para Chile que lo que finalmente se dio. Y ello precisamente porque habría permitido conservar para su dominio buena parte de la tierra adentro del Estrecho revelada en su geografía, sus recursos naturales y su potencialidad por la gente de Punta Arenas (baqueanos, exploradores) y entendida tempranamente como de su dependencia hegemónica. Las informaciones que hubieran podido fundar con razón y fuerza esa argumentación estuvieron a disposición del gobierno de Santiago en forma de relaciones $e$ informes oficiales y testimonios de viajeros desde la primera hora. Se habrían conservado así para Chile distritos mirados como propios desde largo tiempo atrás, tales como las comarcas de la parte sur del lago Santa Cruz o Argentino descubiertas por Zamora y exploradas por Rogers, o las correspondientes a los valles medio y superior del río Gallegos sobre los que transcurrió de manera recurrente la actividad de baqueanos, cazadores y traficantes con los indios. Años después, en 1899, cuando pasó por esa región el eminente geógrafo Hans Steffen -que entonces asesoraba técnicamente al gobierno de Chile para encontrar una solución a la cuestión que había surgido con Argentina con respecto a la ubicación de los hitos

36 Problemas Limitrofes y Viajes de Exploración en la Patagonia. Recuerdos de la época del conflicto fronterizo entre Chile y Argentina (DIBAM-NATIVA EDICIONES- en la frontera andino-patagónica (1888-1902), debido a la distinta interpretación que hicieron las partes sobre lo establecido por el artículo primero del tratado de 1881 -, recordó que tanto la exploración geográfica como la primera fase del desarrollo económico de ese importante distrito subandino (Última Esperanza y aledaños) no habían venido desde el lado del Atlántico, sino desde el sur o desde el oeste y fue emprendido por pioneros que avanzaron desde la localidad chilena de Punta Arenas en el estrecho de Magallanes, en parte por tierra y en parte por mar... ${ }^{36}$.

Es más, con su penetración de especialista, pensando sin duda en lo resuelto con el tratado de 1881 en la zona de que se trata, reflexionó sensatamente que...Chile desaprovechó la posibilidad de una frontera más favorable para sí -refiriéndose a la oportunidad que le había brindado la nueva controversia mencionada- debido a su propia culpa, por mantener su rígida postura frente al principio de la divisoria continental de aguas en la parte sur de la zona de Última Esperanza. El divortium aquarum corre aquí-sobre todo en el tramo entre $51^{\circ} 20^{\prime}$ y $52^{\circ}$ - tan cerca del Pacífico, que la franja costera que permaneció bajo soberanía chilena, debe considerarse como un hinterland absolutamente insuficiente si se piensa en el desarrollo de los puertos de Última Esperanza. Una aplicación sensata del artículo II del Protocolo de Límites de 1893 le hubiera concedido la opción al Tribunal Arbitral de extender la parte de Chile hacia el este hasta el borde la meseta Latorre e incorporar al territorio chileno al menos el valle del río Turbio, uno de los afluentes de origen del río Gallegos, con el camino principal que conduce a Punta Arenas. Pero el perito chileno [Diego Barros Arana], convencido de tener que cumplir en forma consecuente con el principio de demarcación, no pudo apartarse aquí de la línea divisoria principal de aguas presentado en su proyecto fronterizo y el Tribunal Arbitral no podía ir más allá de las líneas extremas propuestas por los peritos, lo que en último término dio como resultado un trazado muy poco satisfactorio para Chile, de hecho pasó a ser este el tramo

Centro de Investigaciones Barros Arana, Santiago 2015), pág. 286. 
que más objeciones merece en toda la larga línea fronteriza en cuanto a la seguridad, la cohesión territorial y las condiciones para el tránsito ${ }^{37}$.

Entonces, tornando a nuestra reflexión inicial, si todo después aparecía como tan obvio ¿por qué no se puso más énfasis en la defensa de ese suelo que había sido revelado y comenzado a ser productivo gracias a la gente de Punta Arenas y que por tanto debía haberse reconocido como legítimamente chileno?

Esta extensa consideración es una suerte de divertimento intelectual acerca de lo que pudo ser en la historia y no lo fue. Bien, pues, pero puede extraerse una conclusión a modo de lección (o experiencia) igualmente histórica como es la reiterada actitud de ignorancia de nuestros gobernantes respecto del territorio nacional, más si es parte de la periferia del mismo. ¡Qué costo ha tenido y sigue teniendo esa actitud!

\section{Período 1881-1900}

\section{a) Desarrollo y afirmación de la ocupación colonizadora}

Al comenzar la novena década del siglo XIX pasó a ser evidente para cuantos en Punta Arenas $y$ en las islas Falkland poseían conocimientos en la crianza ovejera y además de algún capital ahorrado que esa actividad parecía no sólo posible a la vista de los ensayos conocidos, sino además como algo económicamente rentable de cara al porvenir. Henry Reynard había acertado con su iniciativa. Quizá sin haberlo pensado, este inmigrante, por su origen nacional, su educación esmerada y su nivel cultural, se había puesto en sintonía con el fenómeno expansivo económico que la sociedad industrial occidental deseaba (y más quizá la burguesía británica victoriana), o sea, que los territorios de la periferia mundial, como era el caso de la Patagonia, se incorporaran a su proceso productivo como aportantes de materias primas. Así sucedería efectivamente a poco andar con el éxito de la crianza ovina extensiva magallánica y

37 Op. cit. pág. 286. Ver también mapa de la página 274. La referencia final de Steffen corresponde al camino entonces en uso para comunicar el distrito de Última Esperanza con Punta Arenas y viceversa, trazado sobre la senda baqueana y que transcurría como se ve en una parte por suelo argentino patagónica. El mismo Reynard y el Dr. Thomas Fenton, al parecer, fueron quienes establecieron el primer contacto con los importadores y consignatarios de lanas del Reino Unido, condición necesaria para ingresar a ese mercado que con el correr del tiempo pasaría a ser una relación comercial sólida y fructuosa.

Y la gente de Punta Arenas, va de suyo, comenzó a liderar la incipiente expansión pues a los ocupantes que ya se han mencionado, se agregaron otros con ánimo semejante. Tales Mateo Paravic, el primer croata inmigrado en Magallanes, en Cabeza del Mar; Augusto Guillaume, de los franceses arribados a principios de los años de 1870, en Susannah Cove, y los hermanos Henry, William y Stanley Wood llegados por la misma época, que se instalaron a partir de 1883 junto a la desembocadura del chorrillo Kemerokaik (Buque Quemado), enfrentando el gran saco oriental del Estrecho, mientras que Thomas Greenshields, procedente de las Malvinas, lo hacía en la costa de la bahía Santiago entre San Gregorio y punta Delgada, con lo que para entonces en todo el litoral fretano desde Cabo Negro hasta la bahía Posesión se veían surgir las instalaciones de las pequeñas estancias de crianza ovejera extensiva. No cabe pasar por alto lo acontecido durante 1882 en San Gregorio donde los ocupantes originales, Andrieu y Roig, transfirieron sus derechos e instalaciones al español José Menéndez, ya importante empresario comercial de Punta Arenas, el que a partir de entonces haría de ese establecimiento en pocos años con gran inversión de capital y la introducción de una buena tecnología una importante y prestigiada estancia ganadera, todo un modelo a imitar.

El proceso poblador, ciertamente, cobró un dinamismo propio y cada vez fueron más los que de diferente manera se vieron involucrados en el mismo bien como hacendados o proveedores y prestadores de servicios varios. La demanda por terrenos, solo en lo que se refería al territorio chileno (después del tratado de 1881) significaba ya una amplia extensión por todo el flanco sur

debido a que las condiciones naturales, la espesura del bosque y la presencia de turbales, impidieron por años la construcción del tramo caminero correspondiente por suelo chileno, situación que pudo hacerse efectiva recién a contar de 1930. 
desde el mar de Skyring por el oeste hasta monte Dinero y punta Dungeness en el comienzo del Estrecho, con una ampliación tierra adentro por los campos de la Vaquería del Norte, la cuenca de la laguna Blanca, los valles de Dinamarquero, El Bautismo y Ciaike otrora recurridos cazaderos de los aónikenk y las llanuras al interior de la Primera Angostura hasta las primeras elevaciones meséticas. Tanto fue así que la demanda por terrenos debió ser regularizada pasándose de la libre ocupación y tenencia precaria a otra en forma con concesiones reguladas por arrendamientos del fisco y por plazos que iban entre quince y veinte años. Ello se concretó en 1884 con una primera subasta que comprendió un total de 16 unidades o lotes en el sector que interesa, con una extensión de 522.000 hectáreas, algo en verdad impensable un lustro antes.

Entre los nuevos estancieros los venidos de las Falkland o Malvinas hicieron un buen contingente, todos con ganas, conocimientos y algún capital expresado principalmente en animales ovinos adquiridos ex-profeso en la colonia británica. Estos en una menor parte se establecieron en suelo chileno y en otra mayor en el argentino. Varios lo hicieron espontáneamente pero otros respondieron a la invitación que en tal sentido les hizo el gobernador de Santa Cruz Carlos M. Moyano (1885), quien también simultáneamente había pedido a la gente de Punta Arenas que se estableciera como pobladores allende la frontera internacional. De esa manera poco a poco, oleada tras oleada de colonos con ímpetu pionero fueron ocupando los extensos campos situados en la cuenca del río Gallegos hasta el deslinde con Chile, y los ubicados en la amplia cuenca del río Coyle y sus tributarios, y la franja litoral entre los estuarios de aquel curso y el del Santa Cruz, así como en el atractivo y lejano distrito del sur del lago Argentino. Con ello se llenó cronológicamente lo que restaba de los años de 1880. Durante la década final del siglo, el impulso lejos de detenerse pareció acelerarse en la medida que el negocio criador se apreció como una fuente de rápida riqueza según se comprobaba con el éxito económico de cuantos habían corrido el riesgo de la experiencia productiva, en su mayoría ahora prósperos empresarios. Así se fueron cubriendo los vacíos que restaban en el territorio sudoriental magallánico y en el vecino santacruceño. Pero lo que en este respecto caracterizó a la época fue en particular lo acontecido en el otrora lejano distrito subandino de Última Esperanza afamado tempranamente por la abundancia de caballos baguales, por la abundancia de recursos naturales y por la esplendidez de sus paisajes.

El proceso colonizador comenzó con Hermann Eberhard, un antiguo marino mercante alemán radicado en Puerto Stanley (Is. Falkland) que había poblado inicialmente primero en campos del río Chico al suroeste del estuario del río Gallegos (Markatch-Aike) y que además se interesó por conocer el distrito subandino mencionado por los rumores que lo afamaban. Obtenida la autorización del gobernador de Magallanes (1893), realizó una expedición invernal que lo llevó por mar hasta el fiordo de Última Esperanza, cuyas comarcas litorales apreció como aptas para la crianza ovina; peticionó entonces terrenos en el sector que llamó Puerto Consuelo e inició en 1894 su colonización por la vía terrestre siguiendo la antigua ruta de los baqueanos. Con él arribaron otros inmigrantes alemanes igualmente emprendedores como Rodolfo Stubenrauch, Hermann Kark y Ernesto von Heinz y otros compatriotas, y algunos británicos, John Tweedie, Eduardo Craig, George Paton y Walter Ferrier, quienes conformaron la primera corriente pobladora que se estableció en los mejores campos del interior norte del distrito. A estos siguió una nueva oleada y después otra integrada por gente arribada a Punta Arenas como inmigrantes (otros alemanes y británicos, algunos franceses y chilenos) que durante lo que restaba del siglo ocuparon los terrenos vistos como aptos para la crianza pastoril que se hallaban vacantes, por el norte, el oeste y el sur del distrito.

Para entonces, 1900, lo acontecido era motivo de sorpresa y más de admiración para quien hubiera tenido ocasión de informarse sobre lo que antes de 1890 era aquella parte del territorio magallánico, un yermo salvaje y en su mayor parte desconocido. Por todas partes, allí como en los distritos centrales y orientales situados entre el río Santa Cruz y el estrecho de Magallanes, se podían ver colonos afanosos criando ovinos principalmente pues el país estepario se prestaba bien para ello. Esa realidad desmentía a gritos la esterilidad de la tierra patagónica sentenciada por Darwin en 1833 y repetida hasta la saciedad por 
la ignorante corte de sus corifeos que se las habían dado de geógrafos.

De esa manera, siguiendo esos avatares, el proceso de ocupación paulatina del distrito centro-oriental de Magallanes -territorio histórico aónikenk-durante el lapso 1875-1900 se hizo de manera tranquila en general, en medio de un fenómeno coetáneo de irreversible reducción de la población indígena, circunstancia que hizo posible que su ancestral dominio cambiara de manos de manera pacífica, sin traumas ni acciones violentas. Nos parece cosa importante destacarlo nuevamente, como lo hacemos.

\section{b) Nuevas exploraciones}

El quinto final de la centuria décimonona registró nuevas y sucesivas exploraciones dirigidas a mejorar paulatinamente el conocimiento de la tierra adentro sudpatagónica y de sus recursos. Unas, como la conducida por el ingeniero Alejandro Bertrand, con carácter de oficial pues había sido dispuesta por el gobierno de Chile con el objeto de tener una información tan completa como fuera posible de conseguir sobre la parte accesible del territorio que había sido reconocido como de pertenencia nacional por el tratado de 1881, se desarrolló durante los primeros meses de 1885 y sería conocida en los anales como "Expedición a la Región Central de las Tierras Magallánicas". Pero otras, como la encabezada en 1883 por el teniente de la Armada Argentina Carlos M. Moyano, que se inició con idéntico propósito respecto del territorio asignado al país del Plata, en particular las cuencas de los ríos Gallegos y Coyle, cobró un nuevo interés una vez que durante el curso de la penetración del valle del primero hacia el oeste se alcanzó el litoral del fiordo de Última Esperanza (aguas del Pacífico), advirtiéndose así que ese distrito se sitúa al oriente de la cordillera de los Andes y que, en la interpretación de Moyano sobre lo dispuesto por el artículo primero del tratado de límites mencionado, entendió era argentino. Con esa opinión, recogida y adoptada como propia por el gobierno de Buenos Aires, conocer mejor esa geografía fue causa suficiente para otras expediciones. La primera de ellas en 1887 a cargo del también oficial de la Armada Argentina Agustín del Castillo y otras dos, en 1890 y 1892 , dirigidas por Ramón Lista, un explorador con veteranía probada en la Patagonia.

Del lado de Chile y visto el curso de los acontecimientos, en especial después de 1888, Ramón Serrano, capitán de fragata de la Armada de Chile, exploró en 1889 por mar y por tierra según procediera los sectores sur y noroccidental del distrito de Última Esperanza, con gran provecho para el conocimiento de su hidrografía terrestre (en el contexto comprensivo de la divisoria continental de aguas), para permitir sustentar con fundamento la postura interpretativa chilena en la renovada controversia de límites, ahora para determinar el curso de la frontera andina en la Patagonia. Tras la exploración de Serrano tuvieron ocurrencia otras incursiones con propósitos de reconocimiento geográfico específico de algunos sectores. Una de ellas, de carácter privado fue realizada en 1894 por el francés Jorge Meric, antiguo colono radicado en Punta Arenas, sobre el sector meridional del distrito (Llanuras de Diana), y la otra en 1897, otra vez con encargo oficial, la encomendada a los capitanes Alberto Fuentes y Recaredo Amengual de la Armada de Chile, esta vez sobre el sector noroccidental del distrito de Última Esperanza y la zona sudoccidental del lago Argentino para confirmar la independencia de las cuencas hidrográficas que evacúan por el río Santa Cruz hacia el Atlántico y por el sistema del río Serrano hacia las aguas interiores del Pacífico.

Cerró el ciclo de las exploraciones geográficas del siglo la dirigida por el prestigioso geólogo y académico de la universidad de Upsala, Dr. Otto Nordenskjold, conocida en los anales históricos y geográficos como "Expedición Sueca a las Tierras Magallánicas 1895-1897" y que, en lo que interesa, se realizó a comienzos de 1896 por el sector precordillerano noroccidental del distrito de Última Esperanza. La misma tuvo, por vez primera, un carácter propiamente científico en sus objetivos de carácter multidisciplinario pues comprendió estudios geológicos, botánicos y zoológicos además de los propiamente geográficos, y en su bien conducido desarrollo permitió completar con sus descubrimientos, observaciones y registros el conocimiento del territorio de que se trata. Sus contribuciones, valiosas por lo demás, como lo habían sido en diferente grado las expediciones antes mencionadas se manifestaron en informes incluidos en revistas científicas o en publicaciones 
independientes (libros), y en una cada vez más mejorada y actualizada cartografía todo lo que, en su conjunto, permitió a la ciencia geográfica universal y en particular a los gobiernos de Chile y Argentina disponer de un cada vez más completo acervo de conocimientos variados sobre las tierras australes y sus recursos.

Para concluir el punto cabe reiterar el determinante, insustituible y provechoso papel de los baqueanos en el asunto de cuantos en la época histórica de que se trata protagonizaron la aventura del conocimiento geográfico del territorio sudoriental patagónico, como base primera y necesaria de posesión y poblamiento del mismo por parte de los estados nacionales interesados. Sin ellos, definitivamente, los exploradores y viajeros foráneos que los siguieron no habrían podido cumplir con su propio rol divulgador en el ámbito científico.

\section{TRASCENDENCIA DE LA OCUPACION DEL TERRITORIO. LA HEGEMONIA DE PUNTA ARENAS EN EL SUR DE AMERICA}

El cambio de siglos, del XIX al XX, ha sido tratado en varios de nuestros estudios $y$ trabajos como el momento definitorio para diferenciar dos etapas fundamentales en el complejo proceso de poblamiento civilizado y de explotación económica de los recursos del territorio de Magallanes: una correspondiente al período iniciado hacia 1870 que se identifica con el primer impulso que permitió incrementar la población, afirmar su adaptación a las rigorosas condiciones ambientales y dar principio a las primeras actividades de producción económica y ocupar paulatinamente el territorio disponible y colonizable; la otra, que comienza con el nuevo siglo señala una segunda fase más dinámica y agresiva, si cabe el término, camino de su consolidación, con objetivos claros y precisos de acotar el ecúmene productivo, aumentar $y$ diversificar la producción económica y multiplicar la población habitante ofreciéndole mejores condiciones de vida para su satisfactorio desarrollo.

Expuesto así, cabe una particular

38 Gente que había compartido las ideas revolucionarias del movimiento de la Comunne de París tras el establecimiento de la Segunda República luego de la derrota de Francia en la guerra franco-prusiana (1870-71). Los excesos del período consideración sintetizadora para la primera etapa, en tanto que inicial y fundamental pero refiriéndola únicamente al territorio continental sudoriental patagónico otrora trastienda yerma y salvaje de la colonia magallánica y después de 1870 su cada vez más atractivo hinterland.

Procede, pues, hacer un repaso de los factores que a nuestro entender fueron los determinantes del exitoso proceso al tiempo del cambio de siglos.

El primero fue el concerniente al aumento y diversificación de la población territorial no aborigen, fenómeno que comenzó a cobrar una fuerza caracterizadora con la inmigración libre del sexenio 1868-1874 estimulada por las ventajas que para la colonización había establecido el decreto presidencial de noviembre de 1867. Durante ese lapso el número de habitantes de la colonia magallánica se triplicó consolidándose con su primer millar al promediar los años de 1870, aunque con altibajos porque en todo proceso del género si hubo inmigración, también se registró pero en menor grado la reemigración o retorno de algunos de los arribados que o se decepcionaron porque las condiciones alli encontradas no respondieron a sus expectativas, o porque carecieron de la reciedumbre física y moral para afrontar las dificultades y carencias inherentes a una típica situación de frontera de la civilización o, de modo excepcional, porque algunos, los menos, fueron expulsados por ser considerados indeseables como ocurriera con un contingente de communards franceses ${ }^{38}$. Los que se quedaron, en su variopinta composición conformaron el fundamento de la sociedad puntarenense y magallánica: había entre ellos honrados, simples y laboriosos labriegos y pescadores chilotes, los más; chilenos de Aconcagua y un poliforme conjunto de europeos de diferentes nacionalidades, gente mayoritariamente toda trabajadora, con alguna instrucción escolar, conocimientos variados y dominio de artesanías manuales. Aquellos del primer grupo parecieron cumplir en un principio las exigencias del gobernador Oscar Viel para el fomento colonial, pero pronto su carencia de

y la dura represión que siguió fueron razón suficiente para la emigración de los comprometidos, mayormente hacia América. 
Tabla 2. Población Territorio de Magallanes, 1868-1898.

\begin{tabular}{ccccc}
\hline Año & Punta Arenas & Zona rural & Total & Observaciones \\
\hline 1867 & 300 hbs. & - & 370 hbs. & Memoria Gob. Viel \\
1870 & 805 hbs. & - & 805 hbs. & Memoria Gob. Viel \\
1875 & 765 hbs. & - & 765 hbs. & Censo Nacional \\
1885 & 850 hbs. & 1.235 hbs. & 2.085 hbs. & Censo Nacional \\
1895 & 3.227 hbs. & 1.943 hbs. & 5.170 hbs. & Censo Nacional \\
1898 & 7.000 hbs. & 3.000 hbs. & 10.000 hbs. & Est. Gob. Bories \\
\hline
\end{tabular}

instrucción, su ausencia de iniciativas y limitación de miras fueron motivo de su decepción, sin embargo del apoyo que continuó brindándoles, y condujo al mandatario a estimular la inmigración europea en la que puso sus esperanzas de adelanto, determinación que debe ser vista como un gran acierto por sus consecuencias.

El desgraciado motín de los artilleros (noviembre de 1877) significó un frenazo para el proceso de crecimiento demográfico, como podía suponerse, circunstancia lamentable de la que la antigua colonia se fue recuperando poco a poco. Contribuyeron a ello los hallazgos auríferos en la Tierra del Fuego (1880-81) y en la costa del cabo Vírgenes (1884-85) y de modo menos espectacular pero sí más sostenido el influjo que pudo tener el fenómeno del poblamiento colonizador pastoril con sus efectos de creación de oportunidades y puestos de trabajo y de generación de expectativas económicas.

Del seno de ese contingente europeo surgirian una tras otra las iniciativas innovadoras que se han conocido: caza y exportación de pieles de lobos finos, comercio de ramos generales, primeras expresiones artesanales e industriales, introducción de la crianza ovina extensiva, armado y fletamento de naves, en fin. Todo ello, es claro, en grado incipiente y hasta precario en un primer momento, pero tras los ensayos vino su afirmación y expansión, interrelación y multiplicación que permitieron formar las primeras fortunas (José Nogueira, José Menéndez) y pequeños capitales con los cuales se pudo satisfacer a su tiempo las necesidades de inversión. No menos importante fue que en su evolución este proceso hizo posible establecer los primeros contactos mercantiles con plazas distantes como Valparaíso y Montevideo y con algunos grandes puertos de Europa (Portugal,
Gran Bretaña, Alemania y Francia) que devinieron los mercados iniciales para la producción económica territorial que fue cobrando forma y proporciones.

De esa manera cuando el interés por el espacio rural vacío atrajo a los primeros, que intentaron su ocupación económica Punta Arenas y su primera comunidad pudieron responder al desafío y el fenómeno expansivo adquirió una dinámica propia. Con el exitoso ensayo de crianza ovejera la población colonial se volcó literalmente a las zonas rurales, tanto fue así que el número de habitantes que en 1885 superaba las dos mil almas (2.085 habitantes censados entonces), por primera y única vez en la historia regional mostró una distribución distinta, mayoritaria para la parte rural y minoritaria para Punta Arenas.

El poblamiento rural dio origen a una forma de habitar el yermo hasta entonces desconocida en el sur del continente por la gente civilizada. La característica natural esteparia de la inmensa parte del territorio de que se trata no ofrecía a la mano materiales para construir habitaciones e instalaciones por lo que fue necesario llevar desde Punta Arenas todo cuanto era menester. Así madera de construcción, ladrillos, planchas corrugadas de fierro cincado (que pasaría a ser el material que caracterizaría lo edificado); puertas, ventanas, mobiliario, carpas e inclusive para los sectores más desprovistos hasta el combustible para la vida doméstica cotidiana conformaron lo más básico para la construcción y habitación de viviendas, galpones y cuanta otra edificación era requerida para la instalación de un asentamiento colonizador. Añádase a ello lo propio de la explotación económica a desarrollar, esto es, animales ovinos, caballos -imprescindibles en toda faena rural-, algunos vacunos, amén de postes y alambre para corrales, productos químicos para 
atender a la necesidad sanitaria del ganado, herramientas de toda clase en fin. Esas carencias y necesidades obligaron a los nuevos pobladores a vivir de modo austero, autosuficiente y solidario en medio de la soledad y el aislamiento que pudieron ser agobiantes, características exigentes con las que a la larga se dio origen y sustancia a una tradición en cuanto a costumbres y edificación que ha llegado hasta nuestros días con significado y valor de patrimonio tangible o intangible, según el caso.

Acerca de lo que hubo de ser la cotidianeidad y la sociabilidad en ese habitar pionero colonizador en la estepa patagónica austral era prácticamente nada lo que se sabía hasta hace algunos años, pero en época reciente los hallazgos arqueológicos históricos (vestigios de asentamientos, basurales) y el paulatino conocimiento de fuentes escritas que permanecían inéditas (cartas y diarios de vida) permiten rescatar una información valiosa ${ }^{39}$ y bosquejar ese vivir cotidiano. Más se sabía sobre la etnicidad del contingente poblador según lo hemos consignado en varios de nuestros trabajos precedentes, que muestra un abrumador predominio de europeos en su composición, con abundancia de británicos tanto en los titulares de concesiones e iniciadores de los emprendimientos pastoriles como entre los trabajadores, sector donde los escoceses fueron de hecho los únicos por su experticia en el ramo durante los primeros años. Abundan las pruebas indirectas y directas que así lo confirman.

Tanta necesidad de toda clase exigió, en especial durante los tiempos fundacionales de los asentamientos de colonización pastoril, el abastecimiento de artículos, elementos y mercaderías a comerciantes, artesanos o fabricantes para suministrarlos, a los armadores para transportarlos en sus embarcaciones y a los carpinteros para construir lo que fuera menester; todo ello además de la adquisición (en las Malvinas en cualquier caso o localmente si se ofrecía) de la cantidad de ovejas necesaria para comenzar o ampliar una explotación, de los caballos, animales

39 Valgan para el caso citar como los primeros y más interesantes de esos testimonios los debidos a los ovejeros británicos James Radburne (en Herbert Childs, Jimmy el bandido de la Patagonia 1997 (1936); Jack Lively (en Jorge A. Cramer, Por si Quede, 2006); William Blain, ya mencionado, y el baqueano y aventurero William $\mathrm{H}$. esenciales para los establecimientos de campo, algunos vacunos y alambres, postes, herramientas varias y atalajes y otros artículos indispensables para el trabajo rural.

Así entonces Punta Arenas se vio demandada de modo creciente y sostenido para satisfacer tanta necesidad de suministros distintos y de servicios, requerimiento al que pudo responder, circunstancia que repercutió como renovado estímulo sinérgico en el comercio, en sus artesanos y pequeños industriales, en particular en sus aserraderos que afrontaron una demanda superior a cualquier previsión, y por fin en la navegación, haciendo de ese puerto un centro de actividad que a poco andar hubo de sorprender a los viajeros que arribaban a su rada.

En este aspecto particular la ubicación de Punta Arenas en las rutas de tráfico mercante ultramarino Europa-Sudamérica Occidental, su temprana consideración como puerto de escala para el tráfico regular de pasajeros y cargas que fue bien aprovechado desde un principio, le otorgaron territorialmente el carácter de puerta de entrada y de salida obligada, condición que mantendría de manera indisputada por el medio siglo que siguió a $1880^{40}$.

Esa capacidad para responder cada vez mejor a tantos requerimientos que con el transcurrir del tiempo en vez de ceder parecían aumentar según se multiplicaba la actividad dentro y fuera de sus lindes, hizo de Punta Arenas, poco a poco en un principio y de modo notorio hacia el fin del siglo XIX una base potente de sustento para el desarrollo que se generalizaba y extendía por todas partes. Si alguno de los antiguos agoreros y denostadores de profesión de antaño la hubieran visto entonces, cómo se habrían tragado sus palabras. Todo a la vista desmentía a esos falsos profetas del desastre, con las pruebas tangibles de lo que el coraje anímico, la reciedumbre, la tenacidad y la laboriosidad de tantos había sido capaz de construir y proyectar para un mejor porvenir. Es del caso preguntarse qué habría pasado ante esa

Greenwood, varias veces citado.

40 Basta comparar el registro de fondeos que acota el período de que se trata: en 1870 ingresaron a Punta Arenas 61 barcos entre vapores y veleros, con 58.758 toneladas, guarismos que fueron de 655 naves (520 de ellas mercnates) con 813.911 toneladas en 1901. 
indesmentible realidad si la controversia binacional por el dominio del espacio geográfico meridional americano se hubiera retrasado por algunos años en su solución general. Y la respuesta nos aparece clarísima y rotunda desde la experiencia histórica: que Chile, a través de Punta Arenas y su gente, habría negociado en condiciones más equitativas y justas, y obtenido más en consecuencia que lo que le otorgara el arreglo de marras.

Que tal hubiera podido ser en la realidad histórica lo prueba el que la antigua colonia chilena del Estrecho no sólo pudo llevar adelante exitosamente la ocupación y explotación de su hinterland aquende el trazado delimitatorio de 1881, sino sobre su entera vastedad geográfica de cuyo poblamiento colonizador fue un factor determinante con la consecuencia de vigencia de una hegemonía que alcanzaría su tiempo cenital hacia el término de la primera década y principios de la segunda del siglo $\mathrm{XX}$, que se haría sentir benéfica y reconocida por todo lo ancho de su entorno.

Reescribir para poder entender mejor la historia. Quede claro: sin la aprehensión cognitiva previa y sus fases posteriores de ocupación, poblamiento y explotación económica, la historia del territorio nororiental del estrecho de Magallanes habría sido muy distinta a la conocida. Es muy posible que Chile hubiese perdido la mitad del gran canal interoceánico y con ella la sección territorial más importante (incluidos sus cuantiosos recursos naturales entonces inimaginables) y su presencia jurisdiccional habría devenido la propia de un simple enclave remoto sin mayor destino. Por fortuna y no obstante las contrariedades que en el artículo se han recordado se mantuvo lo que más importaba y ello en medida sustancial, fue posible por el esfuerzo, la visión y el trabajo de gente común.

\section{BIBLIOGRAFÍA}

Beerbohm, J. (2004)(1881). Vagando por la Patagonia. Buenos Aires.

Bertrand, A. (1885). Memoria sobre la Rejión Central de las Tierras Magallánicas. Anuario Hidrográfico de la Armada de Chile, vol. XI.

Childs, H. (1997). Jimmy el bandido de la Patagonia. Punta Arenas: Ediciones de la Universidad de Magallanes.
Cramer, J. A. (2006). Por si Quede. Historias de Pobladores y viajeros en la Patagonia Austral contadas en el Fogón por ellos mismos. Buenos Aires: Photo Design.

Darwin, Ch. (1984). El viaje del Beagle. Barcelona: Editorial Labor S.A.

Dixie, F. (1996). A través de la Patagonia. Punta Arenas: Ediciones de la Universidad de Magallanes.

Duble Almeida, D. (1938). Diario de Viaje al río Santa Cruz, Patagonia. Revista Chilena de Historia y Geografía, 92, 208-231 y 93, 254-279.

Grace, G., \& Campbell, D. (2015). Patagonia Bravía. Naturaleza Vida y Aventuras. Memorias originales del baqueano William H. Greenwood. Santiago: Edición propia.

Encina, F. (1959). La cuestión de Límites entre Chile y la Argentina desde la Independencia hasta el tratado de 1881. Santiago: Editorial Nascimiento.

Harambour, A. (2016). William Blain, ovejero en Malvinas y Patagonia. Santiago: Centro Nacional Barros Arana.

Lacoste, P. (2003). La imagen del otro en las P(15342000). Buenos Aires: Fondo de Cultura EconómicaUniversidad de Santiago de Chile.

Lagos Carmona, G. (1980). Historia de las fronteras de Chile. Los tratados de limites con Argentina. Santiago: Editorial Andrés Bello.

Lista, R. (1975). Mis exploraciones y descubrimientos en la Patagonia (1877-1880). Buenos Aires: Marymar Ediciones.

Martinic, M. (1971). Presencia de Chile en la Patagonia Austral (1843-1879). Santiago: Editorial Andrés Bello.

Martinic, M. (1976). La expansión económica de Punta Arenas sobre los territorios argentinos de la Patagonia. Anales del Instituto de la Patagonia, 7, 5-42.

Martinic, M. (1977). La ganadería en Magallanes en su primer cuarto de siglo 1877-1902. Anuario Corriedale de Magallanes-Chile, 14-29.

Martinic, M. (1978). Exploraciones y colonización en la Región Central Magallánica 1853-1920. Anales del Instituto de la Patagonia, 9, 5-42.

Martinic, M. (1979). Patagonia de ayer y de hoy. Punta Arenas: Sociedad Difusora Patagonia Ltda.

Martinic, M. (1979). La política indígena de los gobernadores de Magallanes 1843-1910. AIP. Vol. 10:7-58. Punta Arenas.

Martinic, M. (1980). La ocupación del ecúmene de Magallanes: La colonizacón de las áreas marginales. Anales del Instituto de la Patagonia, 11, 7-46.

Martinic, M. (1981). Estrecho de Magallanes, territorio marítimo chileno. Anales del Instituto de la Patagonia, 12, 
$7-23$

Martinic, M. (1983). Última Esperanza en el tiempo. Punta Arenas: Ediciones de la Universidad de Magallanes.

Martinic, M. (1986). El conocimiento geográfico de la zona austral de Santa Cruz. Revista Patagónica, 27, 41-47.

Martinic, M. (1988). Evelyn Ellis excursionista aventurero en Santa Cruz. Revista Patagónica, 38, 44-45.

Martinic, M. (1992). La población de Magallanes a lo largo de un siglo. Anales del Instituto de la Patagonia, 12, 5-15.

Martinic, M. (1995). Los Aónikenk. Historia y Cultura. Punta Arenas: Ediciones de la Universidad de Magallanes.

Martinic, M. (1999). Los caballos baguales de Última Esperanza. Punta Arenas: Ediciones Universidad de Magallanes.

Martinic, M. (2001). Documentos inéditos para la historia de Magallanes. Anales del Instituto de la Patagonia, 29, 211-233.

Martinic, M. (2002). La participación de capitales británicos en el desarrollo económico del territorio de Magallanes (1880-1920). Historia, 35, 299-321.

Martinic, M. (2002). Marinos de a caballo. Exploraciones de la Armada de Chile en la Patagonia Austral y la Tierra del Fuego. Valparaíso: Universidad de MagallanesUniversidad de Playa Ancha.

Martinic, M. (2004). Viajeros desconocidos en la Patagonia austral durante la década de 1870. Magallania, 32,
5-13.

Martinic, M. (2005). La hotelería en el antiguo Magallanes (1870-1950). Magallania, 33(1), 5-24.

Martinic, M. (2006). El efímero proyecto de la Colonia FrancoChilena del Sur (1875). Magallania, 34(2), 5-10.

Martinic, M. (2006). La exploración de Otto Nordenskjold y su contribución al conocimiento geográfico del interior del distrito fluvio-lacustre de Última Esperanza. Actas $V$ Congreso de Historia Regional de Magallanes (pp. 10-20). Ediciones de la Universidad de Magallanes.

Martinic, M. (2013). Los aónikenk ¿Epítome del buen salvaje? Magallania, 41(1), 5-16.

Martinic, B., \& Roehrs, H. (1991). Hallazgo de una bahía Santiago (Estrecho de Magallanes). Evidencia de relación pionero-indígena. Anales del Instituto de la Patagonia, 20, 45-56.

Moyano, C. (1931). Viajes de Exploración a la Patagonia (1877-1890). Buenos Aires.

Moreno, F. (1964). Viaje a la Patagonia Austral 1876-1877. Buenos Aires: Ediciones Solar-Hachette.

Musters, G. (1964) Vida entre los Patagones. Buenos Aires: Ediciones Solar-Hachette.

Schmid, T. (1964). Misionando por la Patagonia Austral 1858-1865. Buenos Aires: Academia Nacional de la Historia.

Schyte, J. (1855). El Territorio de Magallanes i su colonización. Anales de la Universidad de Chile, 435-455. 